\title{
Evaluation of lowa's Graduated Driver's Licensing Program
}

\section{Final Report}

September 2007

Sponsored by

the lowa Department of Transportation

(CTRE Project 04-181)

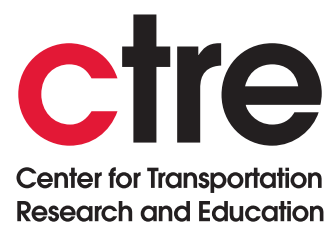

IOWA STATE UNIVERSITY 


\begin{abstract}
About CTRE/ISU
The mission of the Center for Transportation Research and Education (CTRE) at lowa State University is to develop and implement innovative methods, materials, and technologies for improving transportation efficiency, safety, and reliability while improving the learning environment of students, faculty, and staff in transportation-related fields.
\end{abstract}

\title{
Disclaimer Notice
}

The contents of this report reflect the views of the authors, who are responsible for the facts and the accuracy of the information presented herein. The opinions, findings and conclusions expressed in this publication are those of the authors and not necessarily those of the sponsors.

The sponsors assume no liability for the contents or use of the information contained in this document. This report does not constitute a standard, specification, or regulation.

The sponsors do not endorse products or manufacturers. Trademarks or manufacturers' names appear in this report only because they are considered essential to the objective of the document.

\section{Non-discrimination Statement}

lowa State University does not discriminate on the basis of race, color, age, religion, national origin, sexual orientation, gender identity, sex, marital status, disability, or status as a U.S. veteran. Inquiries can be directed to the Director of Equal Opportunity and Diversity, (515) 294-7612. 
Technical Report Documentation Page

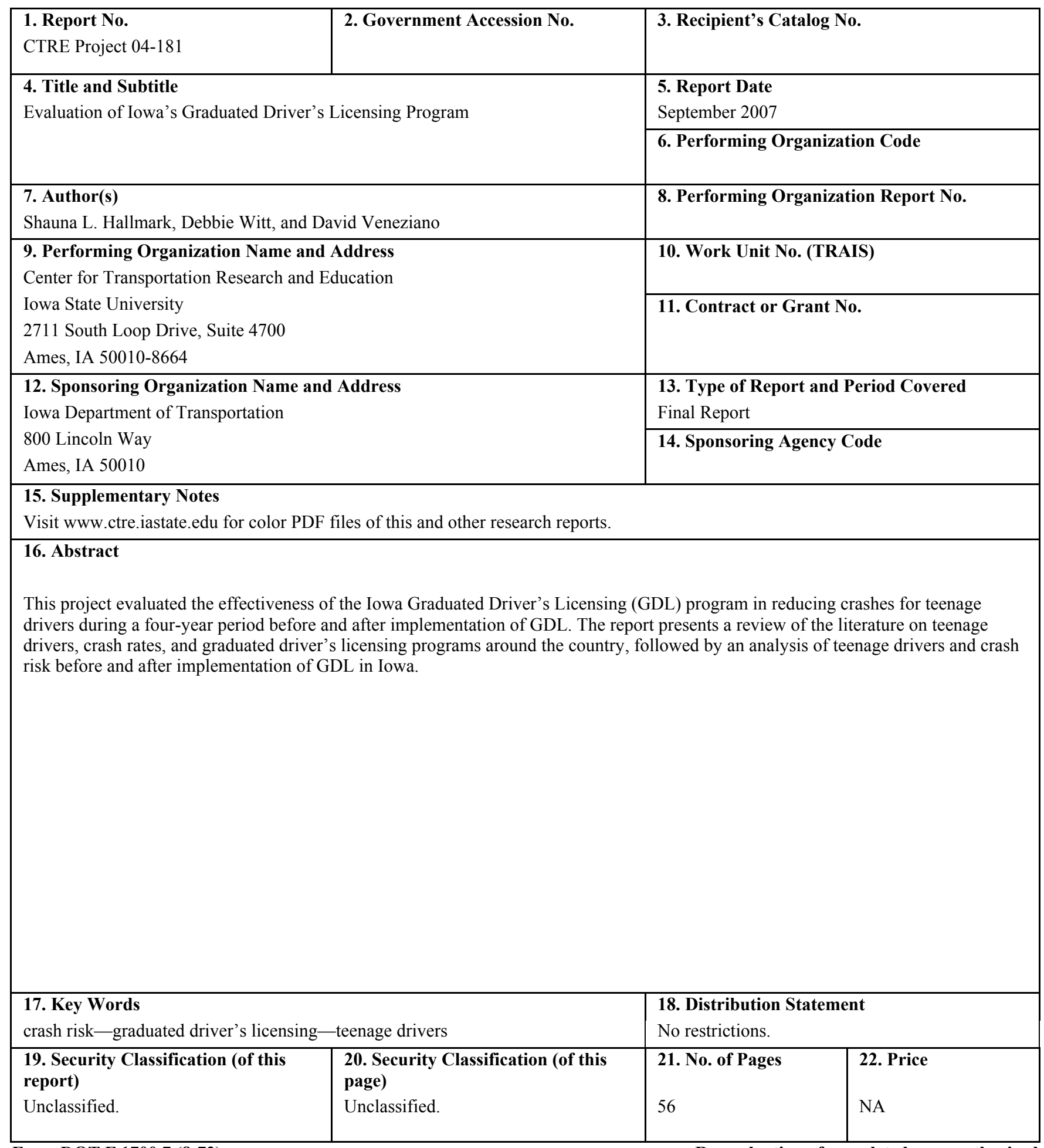




\title{
EVAluation OF IOWA's GRADUATED DRIVER'S Licensing Program
}

\author{
Final Report \\ September 2007 \\ Principal Investigator \\ Shauna L. Hallmark \\ Associate Professor, Department of Civil, Construction, and Environmental Engineering \\ Iowa State University \\ Research Assistants \\ Debbie Witt \\ David Veneziano \\ Authors \\ Shauna L. Hallmark, Debbie Witt, and David Veneziano \\ Preparation of this report was financed in part \\ through funds provided by the Iowa Department of Transportation \\ through its research management agreement with the \\ Center for Transportation Research and Education, \\ CTRE Project 04-181.

\section{A report from \\ Center for Transportation Research and Education Iowa State University} \\ 2711 South Loop Drive, Suite 4700 \\ Ames, IA 50010-8664 \\ Phone: 515-294-8103 \\ Fax: 515-294-0467 \\ www.ctre.iastate.edu
}




\section{TABLE OF CONTENTS}

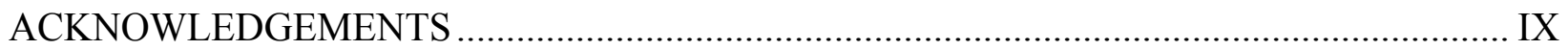

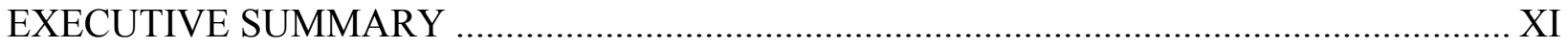

1. CHARACTERISTICS OF YOUNG DRIVER CRASHES .......................................................

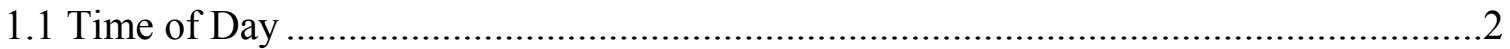

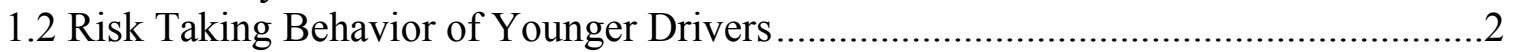

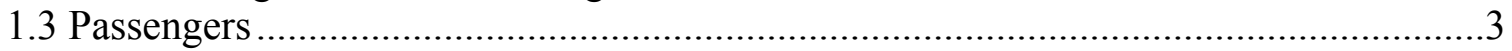

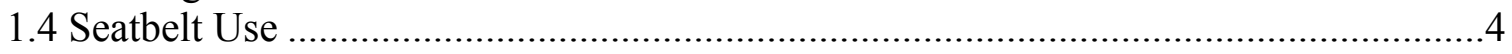

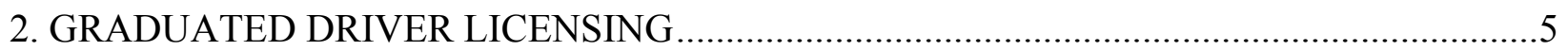

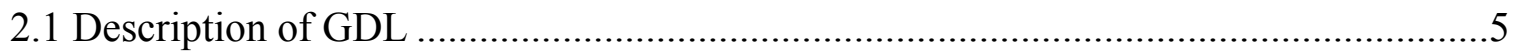

2.2 General Effectiveness of GDL in Other States or Countries .........................................6

2.3 Compliance with GDL Restrictions (Surveys from Other States)...............................11

2.4 Effectiveness of Specific Components of GDL Programs ..........................................12

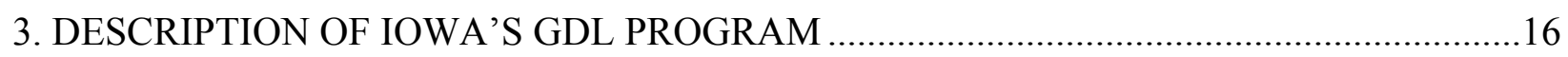

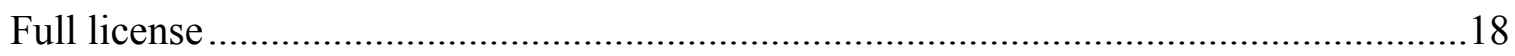

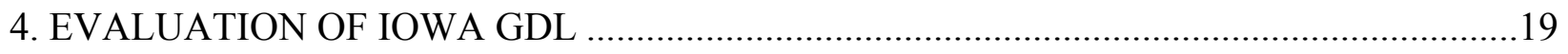

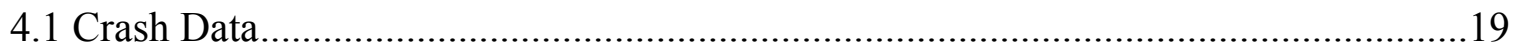

4.2 Total Reduction in Crashes.................................................................................19

4.3 Changes in Crash Severity …………..................................................................22

4.4 Changes in Alcohol/Drug Related Crashes ............................................................24

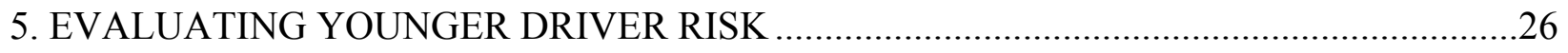

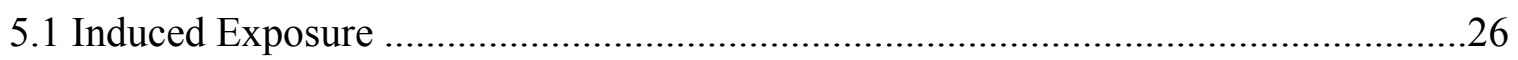

5.2 Over-involvement by Number of Passengers in the Vehicle......................................27

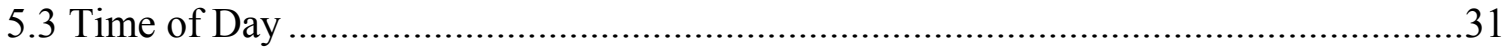

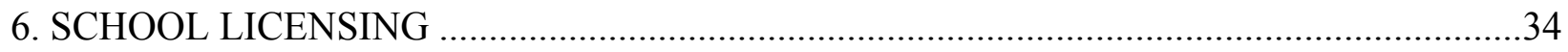

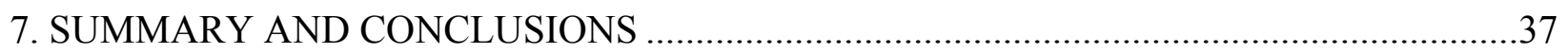

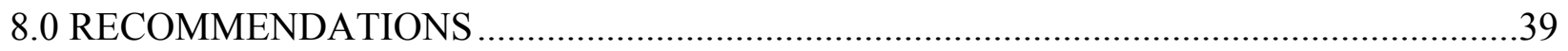

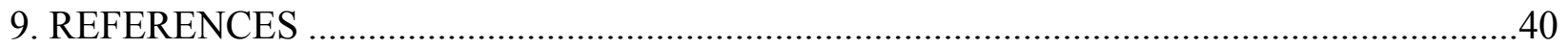




\section{LIST OF FIGURES}

Figure 5.1. Number of occupants with 14-year-old drivers involved in crashes.........................28

Figure 5.2. Number of occupants with 15-year-old drivers involved in crashes..........................28

Figure 5.3. Number of occupants with 16-year-old drivers involved in crashes...........................29

Figure 5.4. Number of occupants with 17-year-old drivers involved in crashes..........................29

\section{LIST OF TABLES}

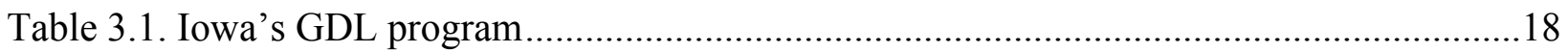

Table 4.1. Crash rate by age group before implementation of GDL .........................................2

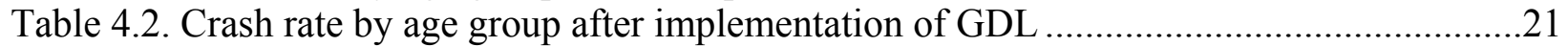

Table 4.3. Drivers involved in crashes with at least one fatality ...............................................23

Table 4.4. Fatalities per 1,000 licensed drivers before and after GDL ....................................23

Table 4.5. Drivers involved in crashes with at least one injury and no fatalities ..........................24

Table 4.6. Injury crashes per 1,000 licensed drivers before and after GDL ..................................24

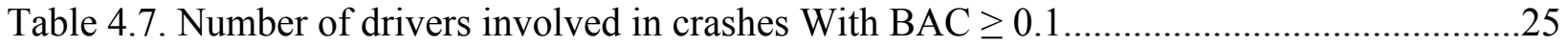

Table 5.1. Induced exposure by number of occupants for 14-year-olds........................................30

Table 5.3. Induced exposure by number of occupants for 16 -year-olds............................................

Table 5.4. Induced exposure by number of occupants for 17 -year-olds......................................... 31

Table 5.5. Induced exposure by number of occupants for 35- to 44-year-olds ...............................31

Table 5.6. Induced exposure by time of day for 14-year-old drivers ............................................32

Table 5.7. Induced exposure by time of day for 15 -year-old drivers ............................................32

Table 5.8. Induced exposure by time of day for 16-year-old drivers .............................................32

Table 5.9. Induced exposure by time of day for 17 -year-old drivers ............................................33

Table 6.1. Crashes for 2002 and 2003 by type of license holder for 14- and 15 -year-olds............35

Table 6.2. Sanctions and moving violations for 14- and 15-year-old drivers by license type for

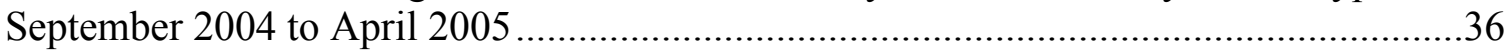




\section{ACKNOWLEDGEMENTS}

The research team wishes to thank the Iowa Department of Transportation for funding this

project. In particular, we would like to thank Mr. Scott Falb and Dr. Michael Pawlovitch of the Iowa DOT for their assistance in completing the project. 


\section{EXECUTIVE SUMMARY}

This project evaluated the effectiveness of the Iowa Graduated Driver's License (GDL) program in reducing crashes for teenage drivers during a four year period before and after implementation of GDL. Some changes had occurred in the crash report form and in the way crashes are reported resulting in fewer reported crashes per year in the after period. In order to determine the effect of implementing the GDL program versus the effect due to changes in crash reporting or other unaccounted for trends, a method suggested by Hauer (1997) was used. This method compares the reduction in crashes for one population due to implementation of a certain strategy to changes in crashes for a static population that is not expected to be influenced by the strategy. Accordingly, the age group 35 to 44 was used as the static population. Since GDL is not likely to affect middle-aged drivers, this age group was assumed to be fairly static; the amount of reduction for middle aged drivers was assumed to represent the average that could be expected due to changes in crash reporting and in general downward trends in the number of crashes for all age groups. If teenage crashes decreased by the same amount as the middle-aged group, it could be assumed that there was no effect due to GDL, since any decreases would be attributed to other factors that affected all age groups. If teenage crashes decreased at a greater rate than the 35- to 44-year-old age group, the assumption could be made that the decrease was due to GDL.

Crash rate per licensed driver was calculated for each age group for the before and after periods. The ratios of crash rate for each teenage driver age group to the 35 to 44 age group were also calculated and compared for the before and after periods. After implementation of GDL, the crash rate for all age groups was lower than in the before period. The 35- to 44year-old age group had a $21.6 \%$ reduction in crashes from the before to after period $(0.055$ to 0.043 crashes per licensed driver). All teenage groups experienced a greater decrease in crash rate than the 35 - to 44-year-old age group, except for the 15 year-olds.

The reduction in crash rate was the greatest for 14 -year-olds. The crash rate was almost $43 \%$ lower in the after period and the ratio of the crash rate for that age group to the 35- to 44year-old crash rate was 0.21 compared to a before ratio of 0.31 . The least reduction in crash rate from the before to after period was for 15 year-old drivers, with a reduction around 15\%, which was lower than the reduction for middle-aged drivers. The ratio of crash rates for 15year-olds as compared to 35- to 44-year-olds actually increased in the after period ( 0.53 after compared to 0.49 before). The crash rate for 16 -year-olds was reduced by $30 \%$ and the ratio of their crash rate to 35- to 44-year-olds was lower (2.95 in the after period compared to 3.31 before). The 17-year-old age group experienced a slightly higher reduction in crashes $(25 \%)$ than 35- to 44-year-olds. The ratio of the crash rate for 17-year-olds to the crash rate for 35to 44 -year-olds in the after period was also lower than in the before period $(2.77$ after compared to 2.80 before).

The number of crashes in the after period that would be expected if each teenage driver group had the same reduction as the 35- to 44-year-old age group was calculated. The actual proportion of crashes to licensed drivers was compared to the proportion of expected crashes 
by comparing differences between two population proportions. Results indicate that, at the $95 \%$ confidence interval, the rate of actual crashes to licensed drivers in the after period is statistically lower for the 14-year-old, 16-year-old, and 17-year-old age groups than the rate of crashes that would have been expected for those age groups if they had the same reduction as the 35- to 44-year-olds. The rate of actual crashes to licensed drivers for the 15-year-old age group is higher than the rate that would have been expected if the same reduction had occurred for that age group as occurred for the 35-to 44-year old age group; this result is statically significant at the $95 \%$ confidence interval.

The fatal crash rate per 1,000 licensed drivers was also calculated for the before and after analysis periods for each age group. The fatal crash rate decreased for 14-year-olds, 16-yearolds, and 35- to 44-year-olds. All differences were statically significant at the $95 \%$ level of significance. Both the 14- and 16-year-olds had a greater decrease in fatal crash rate than the 35 - to 44-year-old age group. Both the 15- and 17-year-old age groups had a slight increase in fatal crash rate per 1,000 licensed drivers. However, the differences were not statistically significant at the $95 \%$ level of significance.

The injury crash rate per 1,000 drivers was also calculated for each age group using non-fatal injury crashes. The injury crash rate decreased for all age groups, except for the 17-year-old age group, from the before to after period. The 17-year-olds had a slight increase in injury crash rate $(3 \%)$. All changes from the before to after period were statistically significant at the $95 \%$ level of significance. Only the 14- and 16-year-old age groups had a decrease that was greater than the decrease for 35- to 44-year-olds.

A number of studies have indicated that younger drivers are disproportionately involved in certain situations. A relationship between crash risk for teenage drivers and the number of passengers (typically other teenagers) has been demonstrated in other studies. The impact of number of occupants was evaluated for each teenage driver group before and after implementation of GDL in Iowa. Some states restrict teen passengers or number of occupants. However, in Iowa there is no limitation on the number of teenage passengers or other passengers that can ride in a vehicle with a teenage driver. The number of occupants is limited only by the number of seatbelts in the vehicle. Drivers with instruction permits are required to have an adult licensed driver present in the vehicle with them unless they have a school license. Each person in the vehicle is counted as an occupant, including the driver.

After GDL, the number of 14-year-old drivers involved in crashes with one occupant (i.e., driver only) decreased from $43 \%$ to $36 \%$ and the number with two or three occupants increased. This is as would be expected, since GDL requires 14-year-olds to drive with a licensed adult, although the age of other occupants is unknown. However, a large number of 14-year-olds who were involved in crashes were still driving alone, despite GDL restrictions. The number of 15-year-old drivers involved a crash who drove alone increased slightly (45\% to $50 \%$ ) after implementation of GDL, even though 15-year-olds are under the instruction permit and are required to have a licensed adult in the car unless they have a school license and are driving alone under the conditions of the school license. 
For 16-year-olds involved in crashes, the number who drove alone decreased and the number with two occupants increased in the after period, even though most 16-year-olds are likely to be under an intermediate permit, which does not require an adult licensed driver. The number of occupants for 17-year-old drivers who were involved in a crash did not change significantly.

The induced exposure method was used to evaluate whether drivers were more likely to be responsible for a crash based on the number of occupants in the vehicle. A discussion of the induced exposure method is described in Section 5.1. The crash involvement ratio was calculated for each age group for one occupant, two occupants, three occupants, and four or more occupants. Beyond the age of the driver, the age of other occupants is not available from the crash records. Only results for the "after" period are discussed in the executive summary.

Fourteen-year-old drivers were more likely to be over-involved in crashes when they drove alone than were drivers in any other category. This suggests that additional benefits could be derived from restricting school licenses, which allow younger drivers to drive alone, and enforcing the requirement to have a licensed adult in the vehicle. In the after period, 15-yearold drivers were more likely to be over-involved in crashes with one or two occupants. Both the 16- and 17-year-old age groups were over-involved in crashes when there were four or more occupants in the vehicle. Although passenger age is unknown, this concurs with other studies indicating that the presence of several other teenage passengers creates a more risky situation for teenage drivers.

Other studies have also suggested that teenage drivers are over-represented during evening hours. The crash involvement ratio was calculated for each teenage group for select time periods during the day, both before and after implementation of GDL. Only results for the "after" period are discussed here.

The time periods where 14-year-olds had an elevated crash involvement were 11 AM to 1 PM, $10 \mathrm{PM}$ to midnight, and 7 to $9 \mathrm{AM}$. The times that 15 -year-olds were most likely to be overinvolved in crashes were midnight to 6 AM, 11 AM to 1 PM, and 7 to 9 AM. Sixteen-year-old drivers were the most over-involved in crashes from 5 to $8 \mathrm{PM}, 8$ to $10 \mathrm{PM}$, and $11 \mathrm{AM}$ to 1 PM. Seventeen-year-old drivers had lower involvement ratios than other teenage groups overall. The times when they were more over-involved were midnight to 6 AM and 7 to 9 AM.

The 11 AM to 1 PM time period may represent lunch trips by teenage drivers if schools have open campuses and the 7 to 9 AM period likely represents trips to school. As indicated, evening trips are still problematic, but school trips appear to be times when teenagers are over-involved in crashes

The impact of the school permit, which allows teenage drivers to drive alone to school, school events, or work, was also examined. The percentage of school license holders per 
licensed driver was relatively constant for 14-year-olds and 16-year-olds from the before to after period. The percentage of school license holders compared to the number of licensed drivers for 15 -year-olds, however, is increasing over time. The percentage of 15 -year-old school license holders in December 1997 was 22.7\%, compared to 30.0\% in December 2003. Although it cannot be quantified, this may help explain why 15 year-old drivers did not seem to benefit from implementation of the GDL program in Iowa.

The number of crashes by 14- and 15-year-old drivers was further analyzed for 2002 and 2003 by license type. Only $6.0 \%$ of 14 -year-old drivers held a school license during that time period, but they were involved in almost $31 \%$ of the crashes where license status was known for that age group. This indicates that they were more than seven times more likely to be involved in a crash than 14-year-olds who were operating under a regular instruction license. Only $28.4 \%$ of 15 -year-old drivers held a school license, but they were involved in almost $71.1 \%$ of the crashes where license type was known for that age group. As a result, 15-yearold drivers with school permits were more than 6.2 times more likely to be involved in a crash than 15 -year-olds who were operating under a regular instruction license.

Information about sanctions and moving violation convictions was also obtained for 14- and 15-year-old drivers for the most recent 6 month period (September 2004 to April 2005). Fourteen- and 15-year-old school license holders were 7.7 times more likely to have one or more sanctions than their peers with regular instruction permits. They were also 4.8 times more likely to receive one or more moving violations.

Future improvements to the GDL program in Iowa may include reconsidering the school license, enforcing the restrictions of the school license, restricting the number of teenage passengers in the vehicle, and expanding nighttime driving restrictions. This is based on results of the research, which indicate that these are problematic situations for young drivers. 


\section{CHARACTERISTICS OF YOUNG DRIVER CRASHES}

Motor vehicle crashes are the leading cause of death for people 15 to 20 years of age, representing about one-third of all fatalities in this age group. In addition, drivers in this age group make up only $7 \%$ of the driving population but are involved in $14 \%$ of all traffic fatalities (NHTSA 2003).

Crash rates are dramatically higher for young drivers than for older drivers. In the United States in 1995, the crash rate per million miles driven for 16- to 19-year-olds was more than double the rate for drivers in their 20 s and more than four times the rate for drivers ages $30-$ 69. The crash rate for 16- and 17-year-olds is particularly troubling; 16-year-old drivers were involved in 34.5 crashes per million miles, compared with 20.2 for 17-year-olds, 13.8 for 18year-olds, and 12.8 for 19-year-olds (Williams 2001).

Ulmer et al. (1997) examined the NHTSA's General Estimate System (1993) for 16-year-old drivers and compared their crash involvement to other teenagers and older drivers. Crash involvement per 1,000 drivers was highest for 16-year-olds, followed by 17 year-olds. The proportion of property damage crashes was consistent among all teenage drivers, while the proportion of fatal crashes involving a single vehicle was the highest for 16 year-olds and then decreased as age increased. Sixteen-year-old drivers were more likely to be involved in single-vehicle crashes and in crashes from 6 PM to midnight; they were more likely to have been charged with a moving violation and to have been responsible for the crash. They were also more likely to be accompanied by other teen passengers than 17-, 18-, or 19-year-olds. Ulmer et al. estimated that $71 \%$ of 16 -year-olds involved in a crash were responsible for the crash, followed by $65 \%$ for 17 -year-olds, $62 \%$ for 18 -year-olds, $58 \%$ for 19 -year-olds, $55 \%$ for 20 - to 24 -year-olds, and $47 \%$ for ages 25 to 49 .

Williams et al. (1997) evaluated fatal crash involvement for 15-year-old drivers for states that require learner's permits for 15-year-olds. Most 15-year olds involved in fatal crashes either did not hold a learner's permit (57\%), or if they had a permit $(60 \%)$ were not supervised. Crashes with 15-year-old drivers typically were single vehicle crashes, occurred late at night (between midnight and $6 \mathrm{AM}$ ), and had a number of passengers present in the car. Driving factors that contributed to 15-year-old fatal crashes included speeding and failure to drive in the proper lane. Drivers who were either not licensed or were unsupervised if they held a permit were more likely to be at fault in a crash. The also found few fatal crashes for drivers who were supervised as required by state law.

Compared to older drivers, younger people are more likely to drive at excessive speeds, follow too closely, violate traffic signs and signals, overtake other vehicles in a risky manner, allow too little time to merge, and fail to yield to pedestrians. Younger drivers are also more likely to put themselves in danger because of risk taking and their reduced ability to handle complex situations. In addition, younger drivers are more likely to be in single-vehicle crashes and crashes involving speeding or driver error. A typical crash scenario involves running off the road and not being able to recover adequately (Williams, 2001). 
In order to combat the number and severity of fatal crashes, a number of states have implemented some form of graduated drivers licensing (GDL) program. A graduated licensing process allows younger drivers to learn the driving process in stages. A GDL also reduces a young driver's exposure to situations that are more hazardous for young drivers, such as driving late at night. The following sections describe characteristics of young driver crashes, as reported in the literature, and discuss the success of GDL programs in other states.

\subsection{Time of Day}

While only about $15 \%$ of the total miles driven by 16- to 17 -year-old drivers occur between 9 PM and $6 \mathrm{AM}$, about $40 \%$ of fatal crashes take place during these hours, according to research by Lin and Fearn (2003). Using national data obtained prior to the enactment of GDL systems, a University of North Carolina study (2000) found that $80 \%$ of 16 -year-old-driver nighttime crashes occurred between the hours of 9 PM and midnight, while $73 \%$ of 17-yearold-driver nighttime crashes occurred from 9 PM to midnight (UNC 2000). The crash risk for 16- and 17-year-old drivers was nearly three times greater between 10 PM and midnight than during the daylight hours. Based on their study, the risk per mile driven is even greater after midnight, since most of the nighttime vehicle miles traveled (VMT) by 16- and 17-year-olds occur before midnight. Ulmer et al. (1997) examined NHTSA's General Estimates System for 16-year-old drivers and found that 16-year-olds were more likely than other drivers to be involved in crashes from 6 PM to 12 AM. Williams et al. (1997) evaluated fatal crash involvement for 15-year-olds and 16-year-olds and found that fatal crashes for 15-year-olds were more likely to occur between midnight and 6 AM. Rice et al. (2004) evaluated how nighttime driving affected injury crash rates for young drivers in California, before implementation of GDL in 1998, and found that crash risk increased after 10 PM.

Since younger drivers have a higher crash risk during late evening and early morning hours, general curfews that limit the nighttime activities of teenagers in the absence of adult supervision have been shown to reduce late night motor vehicle injury involving teenagers, even though the restrictions were not specifically developed or adopted as highway safety measures (Lin and Fearn 2003).

\subsection{Risk Taking Behavior of Younger Drivers}

Adolescent impulsiveness is a natural behavior, but it results in poor driving judgment and high-risk behaviors, such as speeding, inattention, drinking and driving, and not using a seat belt. Peer pressure also often encourages risk taking (USDOT 2004). According to NHTSA, risk taking among adolescents appears to be a critical factor in explaining the high crash incidence. For example, younger drivers tend to accept narrower gaps when pulling out into traffic. In addition, they have been observed to have shorter following distances and to drive at higher speeds (Ferguson). 
Another study found that young drivers are less able to maintain full attention to the driving task and less likely to take in the information they need from the driving environment (Memmer 2000). They are not as good as experienced drivers in scanning the environment and recognizing potential hazards while they are at a safe distance, and they lack the experience and maturity to make complicated driving decisions quickly. They tend to underestimate the danger of certain risky situations and overestimate the danger of others. Most novice drivers' increased risk comes from inappropriate behavior, which includes deliberately taking risk actions, seeking stimulation, driving at high speeds, and driving while impaired. Risky choices result from poor risk perception and an inability to detect hazards, often coupled with overconfidence (Memmer 2000)

\subsection{Passengers}

Crash risk for teenage drivers is associated with the number of passengers in the vehicle they are driving. Williams (2001) reported the results a study indicating that the presence of one passenger nearly doubles the fatal crash risk compared with driving alone. In another study, the fatal crash risk with two or more passengers was five times as high as driving alone. There is excess risk for young drivers with passengers both during the day and at night. The increased risk with passengers present is thought to be largely the result of distraction and risk-taking factors. In vehicles with several young passengers, there is often considerable verbal interaction, music playing, and sometimes physical interactions. Young people are in the beginning stages of driving and inattentiveness to the task can have serious consequences. Many examples provide subjective evidence of inducements to risk taking or showing off in multiple-occupancy crashes involving young people (Williams 2001).

Crash risk for teenage drivers increases with one, two, three, or more passengers. The crash risk with three or more passengers is about four times greater than the crash risk when driving alone (NHTSA 2003). The increased crash risk exists for both daytime and nighttime crashes, although overall crash risk is much higher at night. In one study, death rates from 10:00 PM to 6:00 AM were 1.74 times higher with passengers present than without passengers. During the daytime, rates were 1.77 times higher (Williams 2003). Teens are more likely than older drivers to be involved in fatal crashes when other passengers are in the car (Williams, 2003).

Preusser et al. (1998) evaluated fatal crash drivers of passenger vehicles identified in the Fatality Analysis Reporting System (FARS) for the period 1990-1995. Each driver was categorized either as being alone in the vehicle at the time of the crash or as having one or more passengers. Drivers at fault or responsible for crash occurrence were defined as all drivers involved in a single-vehicle crash, or drivers in multiple-vehicle crashes who were coded in the Fatality Analysis Reporting System as committing one or more driver errors. The results indicated that passenger presence was associated with proportionately more atfault fatal crashes for drivers aged 24 and younger, was a neutral factor for drivers aged 2529 , and was associated with fewer at-fault involvements for drivers aged 30 and older. Relative risk of fatal crash involvement was particularly high for teenage drivers traveling, day or night, with two or more teenage passengers. 
Rice et al. (2003) evaluated injury crash rates for young drivers in California prior to enactment of GDL and found that crash risk increased when young drivers carried three or more young passengers with at least one male. Lam (2003) studied New Zealand crashes where one or more occupant was fatally injured or hospitalized. Results indicated that drivers under the age of 25 with two or more passengers were more likely to be injured in a crash than unaccompanied drivers. None of the studies provided information about how often young drivers travel alone versus traveling with other passengers in the vehicle. Consequently, the amount of travel with or without passengers could not be used as a measure of exposure.

\subsection{Seatbelt Use}

McCartt and Northrup (2004) examined seatbelt use for fatally-injured teenage drivers (16 to 19 years old) from 1995 to 2000 . They found that average belt use was $36 \%$ for fatally injured teenage drivers and $23 \%$ for fatally injured teenage passengers. They found a significant correlation between states with primary seat belt laws. They also found a lower rate of seatbelt use for:

- male teenage drivers;

- teenage drivers of SUVs, vans, and pickups;

- teenage drivers of older vehicles; and

- teenage drivers with blood alcohol concentrations of 0.10 or higher.

Additionally, in crashes involving teenage drivers, the researchers found a lower rate of seatbelt use among teenage drivers in:

- crashes that occurred late at night,

- crashes that occurred on rural roadways, and

- single vehicle crashes.

Seat belt use for teenage drivers also decreased as the number of teenage passengers increased. 


\section{GRADUATED DRIVER LICENSING}

\subsection{Description of GDL}

All young drivers start out with very little knowledge or understanding of all the complexities of driving a vehicle. Like any other skill, learning to drive well takes a good deal of time. Technical ability, good judgment, and experience are all needed to properly make the many continuous decisions that comprise the driving task. GDL programs attempt to make the driving task safer for young drivers in two ways. First, GDL programs allow younger drivers to learn the driving process in stages, providing them with opportunities to gain experience before being confronted with riskier driving situations. And second, driving restrictions keep new drivers out of specific situations that are hazardous (Foss and Goodwin 2003). Specific aspects of GDL to reduce crashes for young drivers are discussed in the following sections.

GDL allows young drivers to gain driving experience in controlled, lower-risk circumstances by enforcing guidelines such as nighttime driving restrictions, passenger limitations, required restraint use for all occupants, and license sanctions that begin at a lower threshold (e.g., first conviction for a serious violation) (NHTSA 2004). These exposure-reducing components work in two ways. First, they allow young drivers to learn gradually under conditions where mistakes or errors in judgment are less severe. Second, they serve as a motivating factor for teens to study for tests, drive safely, and avoid risks in the first place (NHTSA 2004).

Placing limits on teens' mobility may reduce driving exposure, but driving proficiency can be improved through measures that emphasize getting teens behind the wheel to practice. These components encourage the intermediate licensee to make safe driving decisions while driving to reduce risk. They include the following:

- Multi-level instruction coupled with multi-level testing (giving inexperienced drivers the opportunity to first learn and then practice the basics before moving on to learning and practicing more advanced skills)

- Parental guidance

- Driver improvement courses

- Delayed re-testing after failure (NHTSA 2004)

Graduated driver licensing not only helps the novice driver better cope with risks, but also enhances the motivation to drive safely and "play by the rules." Restrictions are lifted as rewards for good driving, and sanctions are imposed for violations. For young drivers, the worst sanction may be the delay that keeps them in an earlier stage longer, while their peers advance to the next level of licensure. By making relief from restrictions contingent upon a good driving record, graduated driver licensing provides incentive to drive safely (NHTSA 2004). 


\subsection{General Effectiveness of GDL in Other States or Countries}

GDL programs have been initiated in a number of states. Initial declines following enactment of GDL programs reflect the combined effects of several factors, only some of whose benefits can be expected to continue. First, there is typically a rush by some young people to become licensed just before GDL takes place. Second, during the initial years of GDL, there is usually a reduction in the amount of driving that teenagers do compared to pre-GDL, due to driving restrictions such as nighttime driving. Since the amount of driving done by teens after implementation of GDL is lower, it is expected that fewer crashes would occur, due to decreased exposure. As this temporary phenomenon works its way through the younger driving population, the enduring benefits of GDL become more apparent. In Florida, for example, the GDL system was implemented in separate pieces rather than as a comprehensive system. As a result of that approach, there was no roll-in, or period during which a combination of factors affected the younger driver population. In 2000, an examination of the effect of these changes found a decline of $9 \%$ in fatal and injury crashes among 15- to 17-year-old drivers (UNC 2000).

The GDL concept was introduced in the 1970s and 1980s through provisional licensing and demonstration programs in Maryland, California, and Oregon. These systems were not threephase GDL programs, but did include some of the GDL features. New Zealand is credited with having implemented the first three-phase GDL program in 1987. For some of the programs, only a brief outline of the results has been published. This section presents descriptions of four programs implemented in other states and countries in chronological order, along with a summary of published results regarding their effectiveness.

\section{Maryland}

Maryland instituted a provisional licensing program in January 1979. Under this program, teens were eligible for a learner's permit three months before their 16th birthday. The learner's permit was valid for three months and supervision was required at all times by a licensed driver who was at least 21 years old. If a driver was at least 16 years of age, a provisional license could be issued, provided that the learner's permit had been in effect for at least 14 days and the applicant had successfully completed driver education and passed an on-road performance test. With the provisional license, driving was restricted between 1:00 AM and 6:00 AM, unless accompanied by an adult. When a driver reached his/her 18th birthday or accumulated six months of conviction-free driving with a provisional license, the driver applied for a regular license (NHTSA 2004).

Maryland changed from the provisional licensing program to "The Rookie Driver: Graduated Licensing System," on July 1, 1999, because the initial GDL program was not as effective as they had hoped. The laws from the new program apply to all non-commercial driver's license applicants, regardless of age, who have never held a license in Maryland or any other state or country, or who have held their out-of-state/out-of-country license for fewer than 18 months. The program requires novice drivers to gain more driving experience with a supervising driver and gradually move up through the licensing process until full license status is 
achieved. Under the graduated licensing system, non-commercial license applicants, who have never held a driver's license, must progress through three licensing levels:

- $\quad$ Level 1 = Learner's permit

- Level 2 = Provisional license

- $\quad$ Level 3 = Full license

Maryland now issues two types of learner's permits. A Type 1 learner's permit is issued to persons who are applying for their first driver's license, with the following restrictions:

- Applicants must be at least 15 years and 9 months of age.

- Applicants under age 18 require the consent (co-signature) of a parent or legal guardian.

- Applicants must pass a vision screening and a knowledge test.

- Type 1 learner's permits are valid for one year.

- Type 1 learner's permits must be held for at least a four-month conviction-free period before the applicant is eligible to test for a provisional license. (A conviction is a moving violation for which you are convicted or found legally guilty. If convicted, the four-month period restarts)

A Type 2 learner's permit is issued to persons who currently hold or have previously held a driver's license and are now applying for a subsequent license, a license of a different class, or a license which requires additional driving capabilities (such as a commercial license, endorsements to operate vehicles which transport passengers, or to remove an air brake restriction). Conditions include the following:

- Applicants must be at least 16 years and 1 month of age.

- Applicants under age 18 require the consent (co-signature) of a parent or guardian.

- Applicants must pass a vision screening and a knowledge test.

- Type 2 learner's permits are valid for six months.

- Type 2 learner's permits must be held at least 14 days before the applicant is eligible to test for a license.

- Applicants applying for a commercial driver's license must meet the age requirements (NHTSA 2004).

\section{California}

In 1983, California implemented a GDL program and evaluated its effect on 16-and 17-yearolds. California emphasized parental involvement. Although teens could get a learner's permit at age 15, they could not get a provisional license until age 16 or a full adult license until age 17. Both driver education and driver training were required, and parents had to certify that the student had completed the required hours of driving practice (NHTSA 2004). 
California's GDL became a law, rather than a program, in July of 1998 and is known for being one of the toughest laws of its kind in the United States. California has the country's first and most stringent passenger restriction (no passengers under age 20 for the first 6 months). It also has a one year nighttime driving restriction (midnight to $5 \mathrm{am}$ ). The California learner's permit is issued for six months, during which time the driver must accumulate 40 hours of driving time with a parent.

Five years after the initiation of the California's GDL program, a report issued by the California Department of Motor Vehicles found that the licensing system contributed to a $5.3 \%$ reduction in the rate of crashes involving drivers ages 15-17 (NHTSA 2004). Since that time, California has adopted a stronger, more effective graduated licensing program that includes a requirement of 50 hours of supervised practice driving, including 10 hours of nighttime driving, during the intermediate license stage (NHTSA 2004).

\section{New Zealand}

In 1985, the New Zealand Ministry of Transport proposed a graduated drivers licensing program with the following objectives:

- To improve the driver preparation of young and inexperienced drivers,

- To encourage formal training,

- To encourage learners to acquire safer driving skills and attitudes,

- To reward safe driving,

- To eliminate the attractiveness of a motorcycle license before or instead of car license,

- To make the system simple and easily enforceable, and

- To create a system that can be continually evaluated (Begg and Stephenson 2002)

New Zealand's proposal was designed to address ways of providing better driver training for driving instructors, encouraging learning drivers to have formal driver training, improving the standard of the licensing tests, and developing a GDL system. These strategies were viewed as more constructive than the frequently-advocated alternative of raising the minimum driving age because they tackled the combination of lack of experience and youth. Although a GDL system was seen as the most controversial strategy proposed, it was also considered the one most likely to contribute to improved road safety (Begg and Stephenson 2002).

New Zealand introduced a GDL system on August 1, 1987. Prior to GDL, teens could apply for a full license at 15 years of age and the application process involved passing written, oral, and practical driving tests. With the introduction of GDL, a three-stage process was introduced: learner license, restricted license, and full license. Teens can apply for the learner license at 15 years of age; to do this, they must pass written, oral, and eyesight tests. With this license, the young driver must be accompanied at all times by a supervisor (parent, 
guardian, or adult). The learner license is held for six months, but the time can be reduced to three months if the learner earns a certificate of competency from a driving instructor.

To obtain the second type of license, the restricted license, teens must pass a practical driving test. There are two main conditions to the restricted license: no driving between $10 \mathrm{PM}$ and 5 AM unless accompanied by a supervisor, and no carrying of passengers unless accompanied by a supervisor. The restricted license is held for 18 months, but the time can be reduced to nine months by completing a defensive driving course or an advanced driving course. After completing the restricted licensing stage, teens can apply for the full license. Violations of the GDL conditions can lead to penalties of up to six months additional time under the learner or restricted license (Srinivasan 2002).

The introduction of GDL in New Zealand was closely followed by a substantial reduction in crash injuries among all ages: 15- to 19-year-olds (23\%), 20- to 24-year-olds (12\%), and 25 years and older $(16 \%)$. The authors argued that the reductions in the 20 years and older age groups suggested that "factors other than the GDL were operating to reduce crashes for all ages, and that the reduction associated with the introduction of GDL among the 15 to 19 year age group was likely to be significantly less than 23 percent." They felt that the reduction in injuries to the youngest age group due to GDL could be between $7 \%$ (23\% minus $16 \%)$ and $23 \%$ (Srinivasan 2002).

Results from New Zealand showed that after GDL was implemented, there was a 23\% decrease in hospitalized injuries among the 15- to 19-year-old age group, $12 \%$ for the 20 - to 24 -year-olds, and $16 \%$ for those 25 and older. If the assumption is made that the $16 \%$ decline evidenced by the 25+ age group represents the decline that would have occurred regardless of whether GDL was implemented, a decline of 7\% for the 15-19 age group was attributed to GDL (Begg and Stephenson 2002). From the results of these evaluations, it seemed that a major impact of GDL was a sharp reduction in the amount of driving by young people, thus reducing their exposure to crash risk. The evidence for this was the sudden decrease in the number of 15-to 19-year-olds with driver's licenses following the introduction of GDL. GDL, therefore, was associated not only with an ongoing decrease in the number of crashrelated injuries to young people, but more importantly with a decrease in the rate per number of licensed drivers. When the study was undertaken, it was not possible to determine whether the actual restrictions of GDL were having an impact on the crash risk or whether this was due to other factors. A further evaluation of GDL was undertaken to try and determine the impact of the driving restrictions on crashes among young drivers (Begg and Stephenson 2002).

A database was created linking the police traffic crash reports to the New Zealand Health Information service (NZHIS) hospital inpatient file. For the analyses, the crashes involving a driver licensed pre-GDL were compared with crashes involving a driver with a restricted license and crashes involving a driver with a full license (Begg and Stephenson 2002). General regression models were fitted for each of the restrictions. Gender, age, and year of crash were controlled for in the analyses. The results showed that, compared with the pre- 
GDL drivers, a significantly smaller proportion of the crashes involving a restricted license driver

- occurred at night (odds ratio .66, $\mathrm{p}=.003$ ),

- involved passengers of all ages (odds ratio .73, $p=.018$ ), and

- included suspected alcohol use (odds ratio .72, $\mathrm{p}=.034$ ).

For the results comparing the pre-GDL driver crashes with the full GDL licensed driver, the only significant difference was fewer nighttime crashes among the full GDL drivers (odds ratio .77, $\mathrm{p}=.04$ ) (Begg and Stephenson 2002). Although the results for the passenger restriction were encouraging, a full evaluation of this restriction was not possible because data on the age of the passengers was only available for those who had been injured (Begg and Stephenson 2002).

\section{Oregon}

In 1989, Oregon began its GDL program. It allows teenagers to get a learner's permit at 15, a provisional license at 16 , and a full license at 18 . The Oregon program emphasizes restrictions on use of alcohol. Suspensions are imposed for any measurable amount of alcohol for anyone under 21. A minimum one-year suspension is also imposed for anyone under the age of 18 convicted of any alcohol or drug offense, which includes possession and/or blood alcohol content. A minimum one-year suspension is also required for any other major traffic violation (NHTSA 2004).

\section{Florida}

The GDL program in Florida was instituted in 1996 for drivers younger than 18. Drivers holding learner's licenses are restricted from driving between $7 \mathrm{pm}$ and $6 \mathrm{am}$. Learner's licenses are held for six months before drivers are eligible for an intermediate license. Nightime driving restrictions for 16 year-olds with intermediate licenses are from $11 \mathrm{pm}$ to 6 am and for 17 year-olds from 1 to $6 \mathrm{am}$. Drivers younger than 18 have a limit on the number of violations that they can accumulate and drivers younger than 21 are subject to a zero tolerance law for drinking and driving. Crash data for Florida teenage drivers from 1995 to 1997 was compared with crash data from Alabama, who did not have a GDL program in place. A 9\% reduction in fatal and injury crashes resulted for the age group 15 to 17 years after implementation of GDL. No reduction was noted for 18 year-old drivers (Ulmer et al. 2000).

\section{Nova Scotia}

Mayhew et al. (2003) examined month-to-month changes in collisions among new drivers in Nova Scotia prior to enactment of a GDL program. They calculated crash rate per driver and evaluated novices (drivers from 6 to 24 months after first licensing) in age groups 16-19 and 20 and older. A regression model indicated that, among novice drivers, the crash rate for 
younger novice drivers was significantly higher during the first few months of driving alone than it was for older novice drivers. They also found that both age groups had a reduction in crash rate as experience increased. Both groups experienced a significant decline in crashes during the first seven months after licensing, but the decrease was larger for novice drivers.

\subsection{Compliance with GDL Restrictions (Surveys from Other States)}

GDL programs are usually well received by the public and by parents, in particular. Several surveys have been conducted in other states about how well GDL programs are received.

\section{Public Opinion}

A 1996 public opinion poll conducted by the American Automobile Association (AAA) found that nearly three out of four respondents favor limiting the use of cars by 15- to-20year-olds until they gain sufficient driving experience. In 1995, the Public Attitude Monitor, an annual poll conducted by the Insurance Research Council, asked respondents to rate various suggestions for reducing auto crashes among young drivers. A graduated driver licensing program was considered a "good" or "excellent" idea by nearly $45 \%$ of all respondents, while $75 \%$ of parents of teenagers liked the idea. Nighttime driving restrictions and zero alcohol tolerance were also highly favored. Interestingly, nearly half of all respondents thought raising the driving age to 18 was a "good" or "excellent" idea (the rate was $60 \%$ for parents of teenagers) (NHTSA 2004).

\section{Parents}

Most parents recognize that teen drivers are at risk, no matter how "good" their children otherwise might be. Support for graduated driver licensing and its components is generally high among parents of teenagers (NHTSA 2004). Parents strongly support graduated driver licensing, despite some minor inconveniences to themselves. More importantly, graduated driver licensing gets parents more involved by asking them to ensure that their children get enough supervised driving practice. The longer period of supervised driving gives parents and teens plenty of opportunities not only to practice but also to discuss driving skills, attitudes and behaviors. Parents also may feel more secure once their teens are fully licensed because they have more experience and maturity to handle difficult situations on the road (NHTSA 2004).

Interviews with 1,253 parents of teens in North Carolina's GDL system indicated that they felt a full year was a reasonable period to require adult supervision of beginning drivers (Foss and Goodwin 2003). When asked specifically about the duration of the learner permit phase, $82 \%$ of parents indicated that 12 months is "about right;" $11 \%$ said it is not long enough. Interestingly, although parents endorse passenger restrictions less strongly than nighttime driving restrictions, many states have implemented highly limiting passenger restrictions. During 2002, 10 states allowed no young passengers to ride with an unsupervised driver during the first several months (usually 6) of unsupervised driving. Most 
other states with passenger restrictions allow no more than one young passenger (Foss and Goodwin 2003).

Little is known about parental enforcement of GDL restrictions. It is known that parents feel empowered by GDL to enforce restrictions that many of them favor, but which are difficult to impose on their child without the backing that a GDL system can provide. Surveys of parents find that most believe their teens nearly always adhere to their license restrictions, but interviews with teens and parents from the same family indicate that parents clearly are not aware of everything their teens do. For example, in North Carolina, 17\% of young drivers reported that they had driven without the required supervisor, but only $5 \%$ of parents were aware their teen had ever driven without a supervisor (Foss and Goodwin 2003).

Simons-Morton and Hartos (2003) surveyed 351 parents of teenagers holding learner's permits in Connecticut about their role in teen driving. They found that parents were more likely to place restrictions on trip conditions (such as destination or length of trip) than on actual risking driving behaviors, such as having a number of teen passengers in the vehicle.

\section{Law Enforcement}

Legal enforcement of GDL restrictions is possible because officers can stop a driver who they believe is underage and check his/her driver's license. They can also enforce GDL when they stop teen drivers for other behaviors, such as speeding. However, more research is needed to illuminate a variety of issues, including how well officers understand the details of GDL, how often they issue citations for violating restrictions, and whether they may be inclined to avoid issuing a citation for minor traffic offenses by restricted drivers in order not to interfere with a teen's progress through the licensing process. In North Carolina, nearly $6 \%$ of teens are convicted for moving violations while driving on an intermediate license, indicating that there is enforcement. This is comparable to the conviction rate for teens with an unrestricted license, but it is not known whether these groups commit violations at a comparable rate (Foss and Goodwin 2003). Additional research is needed to detail the nature and degree of compliance with GDL restrictions as well as the present activities of parents and law enforcement to support and enforce these important elements of GDL (Foss and Goodwin 2003).

\subsection{Effectiveness of Specific Components of GDL Programs}

Most GDL programs have several features that attempt to either allow younger drivers to learn the driving process in stages or restrict young drivers from driving in specific situations that are more hazardous. Common requirements include training, requiring an adult supervisor to be present during early stages of driving, nighttime driving restrictions, and restrictions on teen passengers. The effectiveness of each has been evaluated in other studies. 


\section{Supervised Driving}

A study by McCartt et al. (2001) surveyed juniors and seniors in high school to determine teenage behaviors and attitudes following adoption of GDL in Florida. They found that teenagers licensed under GDL were more likely to obtain permits prior to licensure, hold permits for a longer period of time, and spend more time driving supervised. They also found that the percentage of young drivers who drove 100 miles or less prior to licensure decreased from $26 \%$ to $20 \%$ and the percentage who drive more 500 miles increased from $33 \%$ to $38 \%$ after implementation of GDL. Additionally, the number of teenagers who reported being involved in a crash decreased from $30 \%$ to $27 \%$. The survey also found that the percentage of teenagers who drinking and driving or riding with friends who had been drinking declined after implementation of GDL.

\section{Nighttime Driving Restrictions}

Young drivers have an increased risk of involvement in crashes, including fatal crashes, during nighttime hours. To address this problem, nighttime driving restrictions are generally placed on new or teenage drivers as part of a GDL program to limit their exposure to the higher-risk nighttime driving environment (Lin and Fearn 2003). However, in many states, evening curfews are so late that they still fail to restrict the majority of nighttime trips taken by young drivers. A survey of 16- and 17-year-olds licensed prior to GDL found that only $3 \%$ of their trips occurred from midnight to $6 \mathrm{AM}$. Therefore, a midnight curfew would not apply to the majority of nighttime trips taken by young drivers (Foss and Goodwin 2003).

Nighttime driving restrictions, however, have been shown to effectively reduce the number and severity of crash involvements on the part of teenage drivers. A report in 2002 described a model GDL program for North America, which recommended that unsupervised night driving by newly licensed drivers be restricted, starting with the evening hours, by age for which they are the most likely to be involved in nighttime crashes. For instance, if 14-yearolds show an increased crash rate between 9 and 10 PM, that age group would have restrictions on nighttime driving starting at 9 PM. The optimal recommended starting times are 9 PM to 10 PM, with exemptions for work-related driving and driving to and from school or other non-recreational activities (Lin and Fearn 2003).

Louisiana, Maryland, New York, and Pennsylvania are the four states that are most frequently referenced in studies that assess curfew laws. These states have strong provisions in terms of the range of ages covered, breadth of the curfew hours, and the number of exceptions to the law. The relative impact of state licensure policies, including curfew law, was examined using a comprehensive data set using data from 47 states over a 10 -year period. The effect of implementing a curfew on 15-to 17-year-old drivers was shown to result in a reduction of driver fatality rates of about $28 \%$ for multi-vehicle accidents and $25 \%$ for single-vehicle accidents. Further regression analysis revealed that the curfew significantly reduced the rate of licensure of the study group (Lin and Fearn 2003). 
North Carolina's GDL was instituted in December 1997. To determine the initial effect of the nighttime restriction, the number of 16-year-old driver crashes during restricted hours in 1999 was compared to those in 1997 (Foss and Goodwin 2003). Between 1997 and 1999, crashes in which a 16 year-old driver was killed or seriously injured declined by $39 \%$ during restricted hours and by $27 \%$ during daylight hours. A $44 \%$ decline during nighttime hours also occurred, which shows the benefit of the nighttime driving restrictions. However, the population-based rates declined by $42 \%$ and $30 \%$ for nighttime and daytime crashes, respectively (UNC 2000). There was an even greater relative decrease in crashes of all severity levels during nighttime hours. Total nighttime crashes decreased by $47 \%$ while daytime crashes declined by $22 \%$. Adjusting for population increases, nighttime crashes declined $49 \%$ and daytime crashes decreased by 26 percent. These results clearly show the benefit of North Carolina's 9 PM to 5 AM restriction on driving for inexperienced drivers (UNC 2000).

Florida's nighttime curfew was also found to be effective, with nighttime crash involvements for 15-to 17-year-old drivers declining at a greater percentage rate than daytime crashes. This decline occurred while the number of 15- and 16-year-olds receiving licenses increased by $29 \%$ and $14 \%$, respectively (Lin and Fearn, 2003).

By 2002, 36 states had adopted nighttime driving restrictions. However, the criteria vary widely, ranging from relaxed (1 AM to $5 \mathrm{AM}$ ) to strict (sunset through sunrise). According to an Insurance Institute for Highway Safety (1999) report on the U.S. licensing system for young drivers, seven states (Delaware, Idaho, Mississippi, New York, North Carolina, South Carolina and South Dakota) have nighttime driving restrictions during the intermediate stage of graduated licensing that begin at or before 10 PM and extend until at least 5 AM. Twentynine states have nighttime restrictions that begin later than $10 \mathrm{PM}$; for six of those states, there is only secondary enforcement for the restriction. Fifteen states have no nighttime driving restrictions. The minimum age at which the nighttime restrictions may be lifted varies from state to state, ranging from 16 to 18 years old (Lin and Fearn 2003).

Among the age group of drivers who have begun driving under GDL programs, both the number of crashes and crash rates based on population have declined dramatically. This is, in part, due to nighttime restrictions. As a result of nighttime driving restrictions, crashes during the hours when young driver crash risks are highest have declined even more dramatically. It is still unclear whether this is due solely to the fact that less driving takes place during those hours or whether it is a combination of the reduced exposure along with increased skill and safer driving behaviors developing through the longer learning period that produce greater benefits during higher risk times (UNC 2003).

\section{Driver Education}

Ulmer et al. (1999) evaluated Louisiana's provision that requires 15-year-olds to complete 36 hours of driver education. They found that, with the provision, 33\% fewer licenses were issued to 15 -year-olds. They also found that fatal and injury crash reduction declined by as much as $20 \%$ in the two years after the law took effect. They evaluated other similar states 
(Missouri and Florida) without the same driving provision and found that the crash rate remained the same or increased.

In another study, Ulmer et al. (2001) reported on licensing in Connecticut where 16- and 17year-olds hold learner's permits for six months with no education and for four months if they complete driver education prior to licensure. They compared crash rates before and after implementation of this program to control counties in New York that did not have the same requirements. They estimated crash rate ratio for fatal and injury crashes per 10,000 16- and 17 -year-olds by dividing by crash rate for 25 - to 54 -year-olds as a control group. They found that the crash rate for 16-year-olds decreased by $22 \%$ while the crash rate for 17 - and 18 year-olds did not change significantly. 


\section{DESCRIPTION OF IOWA'S GDL PROGRAM}

The Iowa graduated driver licensing program (GLD) originated from the Iowa Driver Improvement Program (DIP). The DIP was a driver modification class for drivers who had three moving violations or one serious violation within a year. Due to the large number of young drivers sent into the DIP, the state of Iowa implemented a GDL program on January 1, 1999. The purpose of the GDL program was to address the safety issues associated with teenage drivers. Iowa's GDL program parallels the phases recommended by the Insurance Institute for Highway Safety, which include a learner stage, an intermediate stage, and finally, full licensure (IIFS 2001). Iowa's system consists of an instruction permit, intermediate licensure, and full licensure (Iowa DOT 2001). Driver education is required in the instruction permit stage and a remedial driver improvement program is used in the intermediate license stage of the GDL if traffic violations occur or if the driver causes a crash.

Driver education is available at age 14; the teenager must have an instruction permit. To obtain an instruction permit, a teenager is accompanied by a parent/guardian to the Department of Motor Vehicles. Driver education consists of 30 hours of classroom time, including four hours on substance abuse education, a minimum of 20 minutes on railroad crossing safety, and information on organ donation. It also includes six hours of a driving laboratory. A minimum three hours must be behind-the-wheel and up to three hours may be accomplished in a driving simulator.

The intermediate license stage follows the instruction permit. During this stage, if drivers are convicted of a moving violation or contribute to a motor vehicle crash, they are called in for a Remedial Driver Interview. Following the interview, their one-year intermediate status is extended; in addition, they may have new restrictions added to their license, have their license downgraded to their previous license type, or have their license suspended. The following are characteristics of Remedial Driver Improvement:

- The program applies to drivers with either an instruction permit or an intermediate license.

- Drivers will be referred if convicted of one moving violation or involved in an accident to which the driver contributed.

- Both the driver and a parent/guardian must participate in an interview with a Department of Transportation (DOT) official.

- The DOT official may impose additional driving restrictions.

- The driver must begin a 6-month or 12-month accident-and-conviction-free driving period again to qualify for the next licensing level (Iowa DOT, 1999).

Under the system, full driving privileges without restriction cannot be obtained until the age of 17. Restrictions, such as moving violations, remain on 14- to 17-year-olds' records for 30 days to one year. However, under the GDL program, full licensure may be delayed as late as the driver's 18th birthday if he/she has violations on record that have not been revoked. 
The only nighttime driving restrictions that are part of the Iowa GDL are that a licensed driver meeting GDL program requirements accompany the teenage driver between 12:30 AM and $5 \mathrm{AM}$ during the instruction permit and intermediate license phases. No limitation exists on the number of teenage occupants that can ride in the vehicle. The only restriction is that all occupants must wear seat belts, so the number of occupants is limited by the number of seatbelts in the vehicle. Table 3.1 summarizes the features of Iowa's GDL program.

One provision of Iowa's GDL program is that teenagers under 16 are able to acquire a minor's school license, allowing them to travel to and from work, school, and school activities. This provision was included to accommodate students who live in both urban and rural areas. 
Table 3.1. Iowa's GDL program

\begin{tabular}{|c|c|c|}
\hline Phase & Eligibility & Conditions \\
\hline $\begin{array}{l}\text { Instruction } \\
\text { permit }\end{array}$ & $\begin{array}{l}\text { - Available at age } 14 \\
\text { - Written approval of } \\
\text { parent/guardian } \\
\text { - Satisfactory vision screening and } \\
\text { knowledge tests }\end{array}$ & $\begin{array}{l}\text { - Must be held for a minimum of six months } \\
\text { - All driving must be supervised by a licensed driver. May drive only with } \\
\text { parent/guardian, immediate family member over } 21 \text {, driver education teacher, or } \\
\text { driver over } 25 \text { with written permission of parent/guardian } \\
\text { - Number of passengers limited to number of safety belts available in vehicle } \\
\text { - Must complete } 20 \text { hours of supervised driving; minimum of two hours must be } \\
\text { between sunset and sunrise } \\
\text { - Must drive accident-free and conviction-free for six consecutive months immediately } \\
\text { preceding application for intermediate license } \\
\text { - Must complete Iowa approved/comparable driver education course } \\
\text { - No parental waiver of any behind-the-wheel drive time }\end{array}$ \\
\hline $\begin{array}{l}\text { Intermediate } \\
\text { license }\end{array}$ & $\begin{array}{l}\text { - Available at age } 16 \\
\text { - Must meet all conditions of } \\
\text { instruction permit } \\
\text { - Written approval of } \\
\text { parent/guardian }\end{array}$ & $\begin{array}{l}\text { - Must be held for a minimum of } 12 \text { months } \\
\text { - May drive: } \\
\text { - Without supervision from } 5 \text { AM to 12:30 AM } \\
\text { - Between 12:30 AM and } 5 \text { AM only with a licensed driver who is a } \\
\text { parent/guardian, immediate family member over 21, or designated adult over } 25 \\
\text { - With a waiver, may drive between 12:30 AM and } 5 \text { AM to and from work or } \\
\text { school-related extracurricular activities } \\
\text { - Must complete } 10 \text { hours of supervised driving; minimum of two hours must be } \\
\text { between sunset and sunrise. The supervision must be by a licensed driver who is a } \\
\text { parent/guardian, immediate family member over } 21 \text {, or designated adult over } 25 \\
\text { - Number of passengers limited to number of safety belts available in vehicle } \\
\text { - Must drive accident-free and conviction-free for } 12 \text { consecutive months immediately } \\
\text { preceding application for full license }\end{array}$ \\
\hline Full license & $\begin{array}{l}\text { - Available at age } 17 \\
\text { - Must meet all conditions of } \\
\text { intermediate license } \\
\text { - Written approval of } \\
\text { parent/guardian }\end{array}$ & - Full driving privileges with no restrictions \\
\hline
\end{tabular}




\section{EVALUATION OF IOWA GDL}

The effectiveness of the Iowa GDL program in reducing crashes was evaluated. Differences in the number and types of crashes in which 14- to 17-year-old drivers were involved are presented in this section. An analysis of the times of day that young drivers were involved in crashes, as well as the number of occupants in the vehicle with the young driver, is presented as well.

\subsection{Crash Data}

Crashes were evaluated for a four-year period before the GDL was instituted and for a four-year period after its implementation. The Iowa GDL took effect in 1999; thus, the before period was made up of crash data for 1995, 1996, 1997, and 1998. Crash data for 1999 were excluded, since some young drivers that year were a product of the GDL and others were not. The after period included crash data for 2000, 2002, 2003, and 2004. The Iowa DOT crash reporting form changed in 2001 and, due to problems during the transition, data quality was uncertain. Consequently, crash data for 2001 were not used in the analysis. Crash data were provided by the Iowa DOT.

Crash data were analyzed for drivers from 14 to 17 years old. Any driver who turned 14 or 15 in 1999 would have been subject to full GDL restrictions. As a result, drivers who turned 14, 15, or 16 in 2000 and later would have been subject to the new GDL restrictions. Thus, 2000, 2002, 2003, and 2004 were used as the "after" period for drivers in those age groups. Drivers who turned 16 in 1999 were not uniformly affected by GDL. Some may have fallen under the new restrictions and others may not have. As a result, drivers who were 17 in 2000 may or may not have been subject to GDL. Consequently, the 17-year-old "after" age group used crash data from 2002, 2003, and 2004.

The crash form used to report crashes for Iowa changed in 2001. Certain fields were changed, others were deleted, and some new fields were added. As a result, some discrepancies existed between the way in which crashes were reported before and after implementation of GDL. Reporting requirements for crashes also changed from the before to after period as well, leading to a decrease in the number of yearly crashes reported for the entire state after 2000.

\subsection{Total Reduction in Crashes}

Crashes per licensed driver for each teenage group were compared for the before and after periods. Crashes per licensed driver were calculated using the following formula:

$C_{i}=\frac{\sum \text { crashes for age group } i}{\text { Number of licensed drivers for age group } i}$

As discussed, changes in the crash form and the way crashes are reported resulted in fewer reported crashes per year in the after period. It is expected that the middle-aged driver group represents a stable group. They were used as a comparison group to reflect what happened in 
crashes overall independent of implementation of GDL. If younger drivers' crash rate was not influenced by GDL, they would be expected to have a decrease in crashes that is similar to the middle aged driver group. The decrease in crashes for each younger driver age group was compared to the middle-aged driver group.

The ratio of crash rate for each younger driver age group to the middle-aged group was also calculated by dividing the younger driver crash rate by the middle-aged driver crash rate (i.e. $0.017 / 0.055$ for the 14-year-old age group). If GDL had no effect, the ratio of younger driver to middle-aged driver crash rate would be expected to be similar in the before and after period.

Crash rates for each age group were calculated for the before and after periods and are provided in Tables 4.1 and 4.2. Before implementation of GDL, the crash rates per licensed driver for 14and 15-year-old drivers were somewhat lower than the crash rate for the middle-aged group. The ratio of the 14-year-old driver crash rate to the 35 - to 44 -year-old driver crash rate was 0.32 $(0.017 / 0.055)$ and the ratio of 15 -year-old driver crash rate to the middle-aged driver crash rate was $0.49(0.027 / 0.055)$. The 16- and 17-year -old drivers had crash rates that were significantly higher than the middle-aged age group before implementation of GDL. The ratio of the 16-yearold crash rate and the ratio of the 17-year-old crash rate to the crash rate of 35- to 44-year-old drivers was 3.31 and 2.80 , respectively $(0.182 / 0.055$ and $0.154 / 0.055)$.

After implementation of GDL, the crash rate for all age groups was lower than in the before period. As shown in Tables 4.1 and 4.2, the 35- to 44-year-old age group had a $21.6 \%$ reduction in crashes from the before to after period ( 0.055 to 0.043 crashes per licensed driver). As shown, all teenage groups experienced a greater decrease in crash rate than the 35- to 44-year-old age group, except for the 15-year-olds, who experienced a smaller reduction. The reduction in crash rate was the greatest for 14-year-olds. The crash rate was almost $43 \%$ lower in the after period and the ratio of the crash rate for that age group compared to the 35- to 44-year-old crash rate was 0.21 after GDL, compared to a before ratio of 0.31 . The smallest reduction in crash rates from the before to after period was for 15 -year-old drivers, with a reduction around $15 \%$, which was lower than reduction for middle-aged driver. The ratio of crash rates for 15-year-olds as compared to 35 - to 44 -year-olds actually increased in the after period ( 0.53 after compared to 0.49 before). The crash rate for 16 -year-olds was reduced by $30 \%$ and the ratio of their crash rate to 35 - to 44 -year-olds was lower (2.95 in the after period compared to 3.31 before). The 17-yearold age group experienced a slightly higher reduction in crashes $(25 \%)$ than 35 - to 44 -year-olds. The ratio of the crash rate for 17-year-olds to the crash rate for 35- to 44-year-olds in the after period was also lower than in the before period ( 2.77 after compared to 2.80 before). All decreases were statistically significant at the $95 \%$ level of significance using a test to compare differences in proportions. 
Table 4.1. Crash rate by age group before implementation of GDL

\begin{tabular}{lcc}
\hline Age group & $\begin{array}{c}\text { Crash rate before } \\
\text { (crashes/licensed driver) }\end{array}$ & $\begin{array}{c}\text { Ratio of younger driver crash } \\
\text { rate to 35- to 44-year-olds }\end{array}$ \\
\hline 14-year-olds & 0.017 & 0.31 \\
15-year-olds & 0.027 & 0.49 \\
16-year-olds & 0.182 & 3.31 \\
17-year-olds & 0.154 & 2.80 \\
35- to 44-year-olds & 0.055 & \\
\hline
\end{tabular}

Table 4.2. Crash rate by age group after implementation of GDL

\begin{tabular}{lccc}
\hline Age group & $\begin{array}{c}\text { Crash rate after } \\
\text { (crashes/license } \\
\text { d driver) }\end{array}$ & $\begin{array}{c}\text { Ratio of younger driver } \\
\text { crash rate to 35- to 44- } \\
\text { year-old driver crash rate }\end{array}$ & $\begin{array}{c}\text { Decrease in crash } \\
\text { rate from before } \\
\text { to after period }\end{array}$ \\
\hline 14-year-olds & 0.009 & 0.21 & $42.9 \%$ \\
15-year-olds & 0.023 & 0.53 & $15.3 \%$ \\
16-year-olds & 0.127 & 2.95 & $30.2 \%$ \\
17-year-olds & 0.119 & 2.77 & $25.3 \%$ \\
35- to 44-year-olds & 0.043 & & $21.6 \%$ \\
\hline
\end{tabular}

As discussed, changes had occurred in the crash form and reporting requirements which resulted in fewer crashes being reported for the years after 2000. Additionally, effects other than GDL (such as improved maintenance or enforcement) may have been responsible for overall reductions in crashes. As a result, simple comparison of the crash rates before and after implementation of GDL does not provide an accurate measurement of the effect of GDL. The crash rate for 35 to 44 year old drivers decreased by $21.6 \%$ in the after period. Some of the reductions may be due to other improvements in safety, but it is expected that a certain amount of this reduction reflects the change in crash reporting.

In order to determine the effect of implementing the GDL program versus the effect due to changes in crash reporting or other changes, a method suggested by Hauer (1997) was used. This method compares the reduction in crashes for one population due to implementation of a certain strategy to changes in crashes for a static population that is not expected to be influenced by the strategy. The static population represents overall trends in the crash rate or number of crashes overall. Accordingly, the age group 35 to 44 was used as the static population; younger driver crashes were compared to middle-aged drivers before and after implementation of GDL.

Since GDL is not likely to affect middle-aged drivers and crash rates for this age group were assumed to be fairly static, the amount of reduction for middle-aged drivers was assumed to represent the average that could be expected due to changes in crash reporting and in general downward trends in the number of crashes. The assumption was made that general downward trends would be reflected in all age groups, including teenage drivers. By comparing teenage drivers to the 35- to 44-year-old age group, it is possible to determine whether teenage crashes are decreasing at a similar or higher rate. If teenage crashes decreased at a similar rate, it could be assumed that there was no effect due to GDL; any decrease would be attributed to other 
factors that affected all age groups. If teenage crashes decreased at a greater rate than the 35- to 44-year-old age group, the assumption could be made that the decrease was due to GDL.

In order to determine whether the differences in crash rate reduction were likely a result of GDL and not the change in crash reporting, and to validate that those differences are statistically significant, a statistical test to infer differences between two population proportions was used (Ott and Longnecker 2001). The actual number of crashes per licensed driver in the after period for each age group was compared to the expected number of crashes per licensed driver that would have occurred if the younger driver group examined had a similar reduction in crashes to the 35- to 44-year-old group. The expected number of crashes was calculated using the following equation:

$$
C_{i \_ \text {expected }}=\mathrm{N}\left(1-r_{35 \text { to } 44}\right)
$$

where:

$C_{i \_ \text {expected }}=$ expected number of crashes for age group $i$ assuming the same reduction in crashes as for 35 to 44 year old drivers

$\mathrm{N}=$ number of licensed drivers in the after period

$r_{35 \text { to } 44}=$ reduction in crash rate for drivers aged 35 to 44 from the before to after period

The actual proportion of crashes to licensed drivers was compared to the proportion of expected crashes to licensed drivers by comparing differences between two population proportions (Ong and Longnecker 2001). Results indicate that, at the 95\% confidence interval, the actual proportion of crashes to licensed drivers is statistically lower for the 14-year-old, 16-year-old, and 17-year-old age groups than the expected proportion of crashes for those age groups if they had experienced the same reduction in crashes as the 35- to 44-year-olds. The proportion of actual crashes to licensed drivers for the 15-year-old age group is higher than the proportion that would be expected if the same reduction had occurred for that age group as for the 35- to 44year-age group and is statically significant at the $95 \%$ confidence interval. The results indicate that GDL was effective in reducing crashes for 14-, 16-, and 17-year-olds. Results also indicate that the 15-year-old driver age group actually had more crashes per licensed driver in the after period than they would have had if they had followed a trend similar to middle-aged drives.

\subsection{Changes in Crash Severity}

Changes in crash severity were also evaluated. Crashes were classified as fatal, inury, or property damage only (PDO) crashes. A crash with one or more fatalities was classified as a fatal crash, a crash with no fatalities and at least one person injured was classified as an injury crash. It is assumed that the reporting of fatal and injury crashes remained consistent between the before and after period since the reporting injury crashes was not affected by the change in reporting.

Table 4.3 shows the number of drivers, by age group, who were involved in a fatal crash for the before and after periods. It should be noted that these values indicate drivers involved in a fatal crash, not total number of fatalities. The number of drivers overall involved in fatal crashes 
decreased by $13.8 \%$. For drivers 35 to 44 , fatal crash involvement decreased by $25 \%$. The number of 14-year-old drivers involved in fatal crashes decreased from 10 in the before period to zero in the after. The number of 15-year-old drivers involved in fatal crashes increased from 15 to 16 from the before to after period (an increase of 6.3\%). The 16-year-old age group experienced a $36.6 \%$ decrease in fatal crash involvement, the most significant decrease of all the age groups. Seventeen-year-olds also experienced a large decrease in driver involvement in fatal crashes, with a difference of $28.9 \%$ reported. All of the teenage age groups except for 15 -year olds had a reduction in fatal crashes that was greater than the decrease for middle aged drivers. The results for 14- and 15-year-olds should be used with caution, however, since both had small sample sizes.

Table 4.3. Drivers involved in crashes with at least one fatality

\begin{tabular}{lccc}
\hline Age group & Before GDL & After GDL & Decrease \\
\hline 14 & 10 & 0 & $100.0 \%$ \\
15 & 15 & 16 & $+6.3 \%$ \\
16 & 93 & 59 & $36.6 \%$ \\
17 & 90 & 64 & $28.9 \%$ \\
35 to 44 & 516 & 387 & $25.0 \%$ \\
\hline
\end{tabular}

The fatal crash rate per 1,000 licensed drivers was also calculated (as shown in Table 4.4) for the before and after periods for each age group. The crash rate decreased for 14-year-olds, 16-yearolds, and 35- to 44-year-olds. All differences were statically significant at the $95 \%$ level of significance. Both the 14-year old and 16 year-olds had a greater decrease in fatal crash rate per 1,000 licensed drivers than the 35- to 44-year-old age group. Both the 15- and 17-year-old age groups had a slight increase in fatal crash rate per 1,000 licensed drivers. However, the differences were not statistically significant.

Table 4.4. Fatalities per 1,000 licensed drivers before and after GDL

\begin{tabular}{lccc}
\hline Age Group & Before & After & Change in fatal crash rate \\
\hline 14 & 0.136 & 0.000 & $-100.00 \%$ \\
15 & 0.118 & 0.129 & $+9.93 \%$ \\
16 & 0.616 & 0.423 & $-31.41 \%$ \\
17 & 0.569 & 0.613 & $+7.69 \%$ \\
35 to 44 & 0.307 & 0.248 & $-19.38 \%$ \\
\hline
\end{tabular}

The actual change in fatal crash rate per 1,000 licensed drivers for each teenage age group was compared to the expected reduction in fatal crash rate that would have occurred if that age group had the same reduction in fatal crash rate as middle-aged drivers, using a test of proportionality. Only the 14-year-old age group showed a difference between the actual and expected crash rates that was statistically significant at the $95 \%$ level of significance. 
The number of drivers involved in injury crashes with at least one injury and no fatalities is provided in Table 4.5. Again, it should be noted that these values indicate the number of drivers involved in crashes where there was at least one injury, rather than number of injuries. The decrease for drivers aged 35 to 44 was $26.5 \%$. All teenage groups except for the 15 -year-old age group experienced decreases in the number of drivers involved in injury crashes that were greater than the decrease for drivers 35 to 44. Driver involvement in injury crashes for 14-yearolds decreased by $43.9 \%$. The 16- and 17-year-old age groups experience decreases of $35.3 \%$ and $32.0 \%$, respectively. The 15-year-old age group involvement decreased by $18.9 \%$ from the before to after period, which was a smaller decrease than for 35- to 44-year-old drivers.

Table 4.5. Drivers involved in crashes with at least one injury and no fatalities

\begin{tabular}{lccc}
\hline Age group & Before & After & Decrease \\
\hline 14 & 615 & 345 & $43.9 \%$ \\
15 & 1,377 & 1,117 & $18.9 \%$ \\
16 & 10,427 & 6,747 & $35.3 \%$ \\
17 & 9,121 & 6,200 & $32.0 \%$ \\
35 to 44 & 33,327 & 24,482 & $26.5 \%$ \\
\hline
\end{tabular}

The injury crash rate per 1,000 drivers was also calculated for each age group. As shown in Table 4.6, the injury crash rate per 1,000 drivers decreased for all age groups except for the 17year-old age group from the before to after period. The 17-year-olds had a slight increase in injury crash rate $(3 \%)$. All changes from the before to after period were statistically significant at the $95 \%$ level of significance when differences between population proportions were compared. Only the 14- and 16-year-old age groups had a decrease that was greater than the decrease for the 35- to 44-year-old drivers. Only the 14- and 16-year-old age groups had a decrease that was greater than the decrease for 35 - to 44 -year-olds.

Table 4.6. Injury crashes per 1,000 licensed drivers before and after GDL

\begin{tabular}{lccc}
\hline Age group & Before & After & Change in injury crash rate \\
\hline 14 & 8.35 & 4.53 & $-45.7 \%$ \\
15 & 10.79 & 9.02 & $-16.4 \%$ \\
16 & 69.07 & 48.32 & $-30.0 \%$ \\
17 & 57.69 & 59.39 & $+3.0 \%$ \\
35 to 44 & 19.83 & 15.69 & $-21.0 \%$ \\
\hline
\end{tabular}

\subsection{Changes in Alcohol/Drug Related Crashes}

Tables 4.7 indicates the number of 14- to17-year-olds involved in crashes who were recorded as drinking and driving, before and after implementation of GDL. Table 4.7 shows the number of drives who were given sobriety tests and had results indicating that their blood alcohol concentrations were greater than or equal to 0.1 . Results are only available when officers are able to give a sobriety tests. The total number of drivers with $\mathrm{BAC} \geq 0.1$ increased slightly from 
the before to after period. Results indicate that drivers ages 14 and 16 had reductions in the number of crashes with $\mathrm{BAC} \geq 0.1$ from the before to after period. Increases resulted for 15 - and 17-year-olds. However, none of the differences were statistically significant when the proportion of drivers of a particular age group was compared to the total number of drivers before and after. It should also be noted that the number of drivers for the 14- and 15-year-old age groups was small.

Table 4.7. Number of drivers involved in crashes With $\mathrm{BAC} \geq 0.1$

\begin{tabular}{lccc}
\hline Age Group & Before & After & Change \\
\hline 14 & 2 & 1 & $-50.0 \%$ \\
15 & 6 & 9 & $+33.3 \%$ \\
16 & 53 & 43 & $-18.9 \%$ \\
17 & 95 & 102 & $+6.9 \%$ \\
35 to 44 & 944 & 781 & $-17.3 \%$ \\
Total & 4,207 & 4,327 & $+2.8 \%$ \\
\hline
\end{tabular}

The increase in the number of drivers involved in crashes with blood alcohol concentrations above the legal limit does not necessarily indicate that an increase in drinking and driving has occurred. It may indicate that officers are more aggressive about administering sobriety tests. 


\section{EVALUATING YOUNGER DRIVER RISK}

Younger driver risk is discussed in the following sections. A number of studies have indicated that younger drivers are disproportionately involved in crashes and that certain situations are more risky for younger drivers. Two such situations, identified in the literature, are discussed in the following sections. Both induced exposure and descriptive statistics methodologies were used to evaluate younger driver risk before and after implementation of GDL and to identify areas of risk that could be addressed in future improvements to the GDL program.

\subsection{Induced Exposure}

\section{Description of induced exposure}

The induced exposure method has been suggested by a number of researchers as a means to estimate exposure and to measure whether a group of drives is over-involved in a particular type of crash. The induced exposure method is used to determine exposure by assuming that drivers who are not at fault or not responsible for a crash represent the distribution of all drivers present on the roadway. According to Golias and Yannis (2001), the induced exposure method is based on the assumption that drivers not at fault in a crash are randomly "chosen" from the population of drivers and approximate the distribution of all drivers. The induced exposure method is used to evaluate whether certain groups are more likely to be involved in certain types of accidents. It assumes that the rate at which drivers are at fault is proportional to crash risk (Davis and Yang 2001). Relative accident involvement ratio (RAIR) represents risk of involvement and is calculated by dividing the number of at-fault drivers for a particular situation by the number of not-at-fault drivers. The general formula for the RAIR, as given in Stamatiadis and Deacon (1995), is as follows:

$$
R A I R_{i, j}=\frac{\frac{D 1_{i, j}}{\Sigma \Sigma D 1_{i, j}}}{\frac{D 2_{i, j}}{\Sigma \Sigma D 2_{i, j}}}
$$

In this formula, $i$ represents type $i$ drivers and $j$ represents type $j$ conditions. Therefore, $\mathrm{D} 1_{i, j}$ represents type $i$ drivers that are responsible under type $j$ conditions and D $2_{i, j}$ represents type $i$ drivers that are not responsible under type $j$ conditions. If drivers are at fault in certain types of accidents in the same proportion as they are not at fault, it is assumed that they are not overinvolved. This is indicated by a RAIR of 1 . A RAIR greater than 1 indicates that the number of drivers who are at fault for the situation being studied is greater than that population of drivers. As a result, drivers are over-involved. A RAIR less than 1 indicates that drivers are less likely to be involved in that particular type of accident as compared to their population. 


\section{Methodology to Estimate Induced Exposure}

The induced exposure method was used to determine whether younger drivers were overinvolved in certain types of accidents to estimate the effectiveness of GDL and to identify potential future areas for improvement.

The induced exposure method assigns responsibility in a two-vehicle crash to whichever driver caused or contributed the most to the crash. The Iowa crash database does not include designation of fault, though an attribute that indicates contributing circumstances for individual drivers is available. As discussed in Section 3.2, a determination can be made using this information as to which driver was engaged in the most serious contributing circumstance that led to the crash. Hereafter, the driver in a two-vehicle crash who was assigned the most serious contributing circumstances leading to the crash is referred to as the "responsible" driver, or "Driver 1," and the second driver (who had less serious contributing circumstances) is referred to as the "non-responsible" driver, or "Driver 2."

\subsection{Over-involvement by Number of Passengers in the Vehicle}

A relationship between crash risk for teenage drivers and the number of passengers has been demonstrated in other studies. However, in Iowa, there is no limitation on the number of teenage passengers or other passengers that can ride in a vehicle with a teenage driver. The number of occupants is limited only by the number of seatbelts in the vehicle. Drivers with instruction permits are required to have an adult licensed driver present in the vehicle with them unless they are driving under the condition of a school permit. As a result, it would be expected that most 14- and 15-year-old drivers would have at least two occupants in the vehicle.

Figure 5.1 shows the number of occupants in the vehicle for 14-year-old drivers who were involved in a crash. One occupant indicates that only the driver was present in the vehicle. As shown, before implementation of GDL, the majority of 14-year-old drivers involved in crashes drove alone (43\%). After GDL, the number of drivers with two or three occupants increased. This is as would be expected, since GDL requires 14-year-olds to drive with a licensed adult. No information is available on the age of other occupants; however, the increase in occupants suggests that 14-year-old drivers may be more likely to have an adult in the vehicle after implementation of GDL. However, a large number of 14-year-olds involved in crashes still drove alone $(36 \%)$, despite GDL restrictions. 


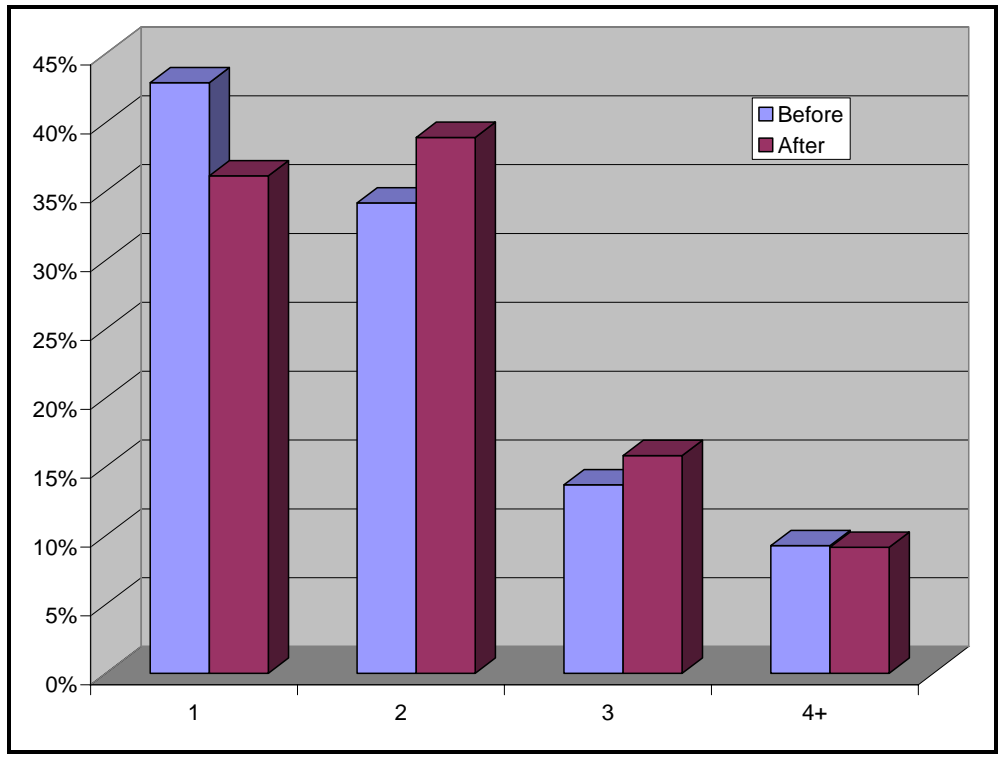

Figure 5.1. Number of occupants with 14-year-old drivers involved in crashes

Figure 5-2 shows the number of occupants in the vehicle for 15-year-old drivers who were involved in crashes. As shown, the number of 15-year-olds who drove alone increased slightly (45\% to 50\%) after implementation of GDL, even though 15-year-olds are under the instruction permit and are required to have a licensed adult in the car. The percentage of 15-year-old drivers with three and four or more occupants did decrease somewhat in the after period.

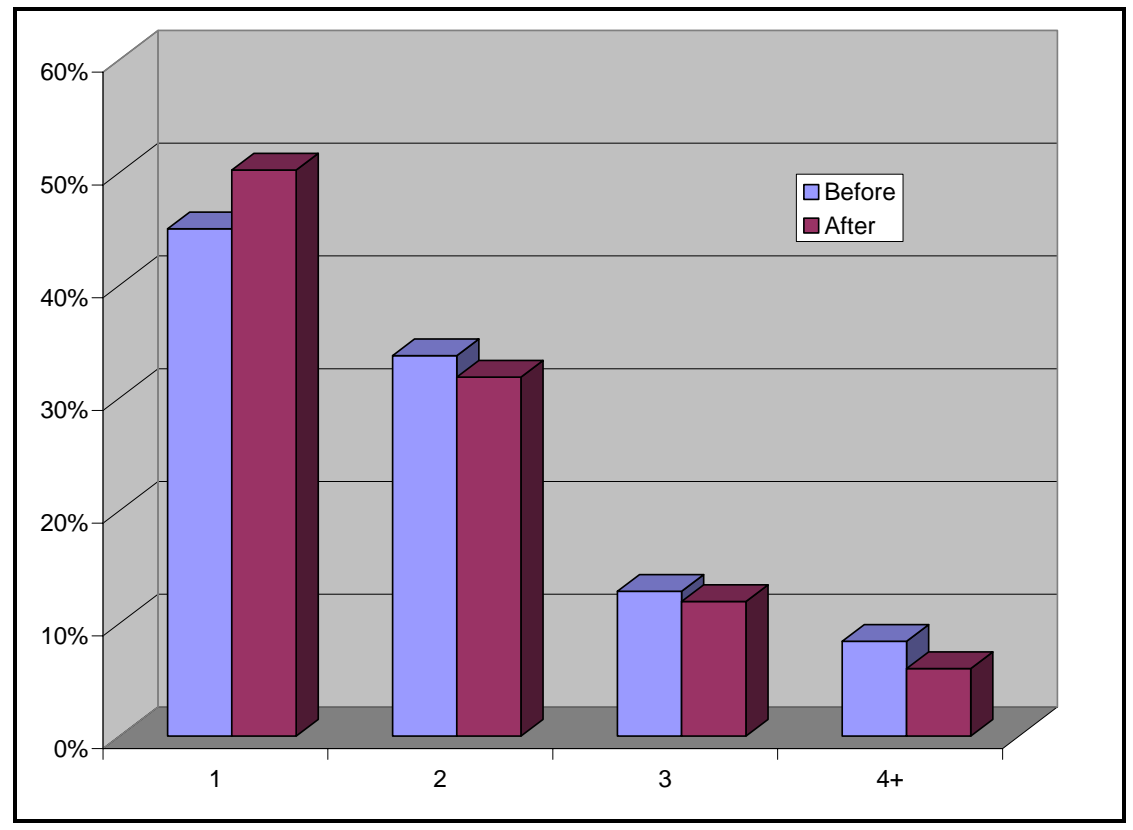

Figure 5.2. Number of occupants with 15-year-old drivers involved in crashes 
Figure 5.3 shows the number of occupants in the vehicle for 16-year-old drivers who were involved in crashes. Interesting, the number of 16-year-olds who drove alone decreased and the number with two occupants increased in the after period, even though most 16-year-olds are likely to be under the intermediate permit, which does not require an adult licensed driver.

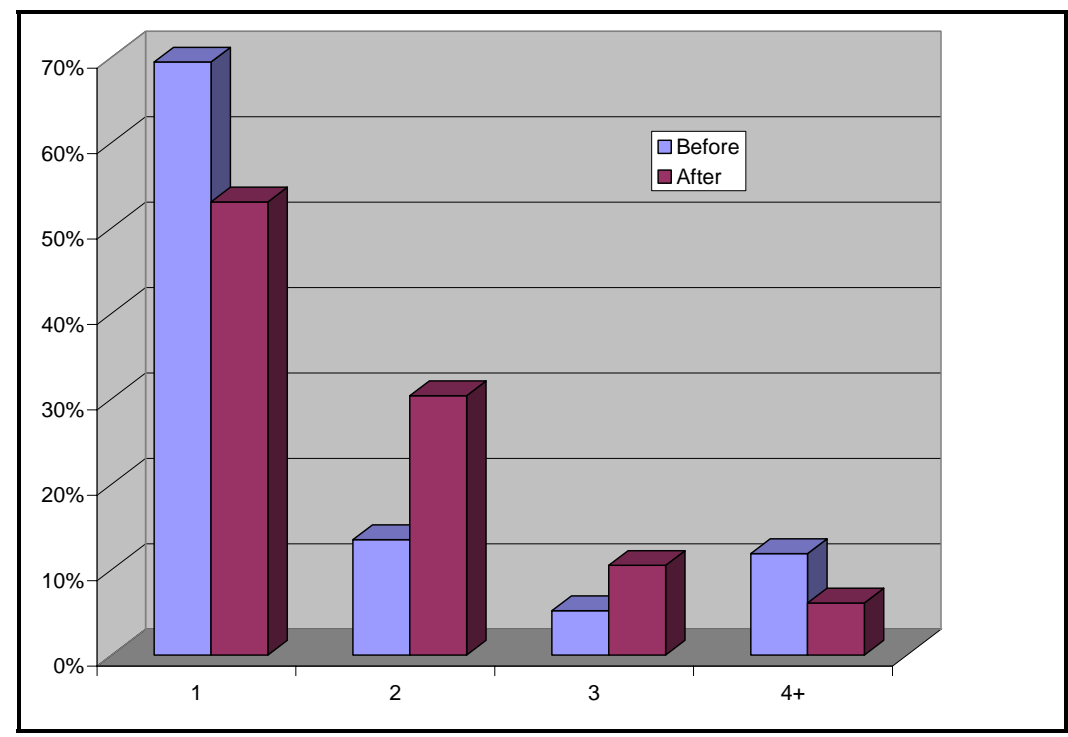

Figure 5.3. Number of occupants with 16-year-old drivers involved in crashes

Figure 5.4 shows the number of occupants in the vehicle for 17-year-old drivers who were involved in crashes. As shown, the number of occupants for any category did not change significantly.

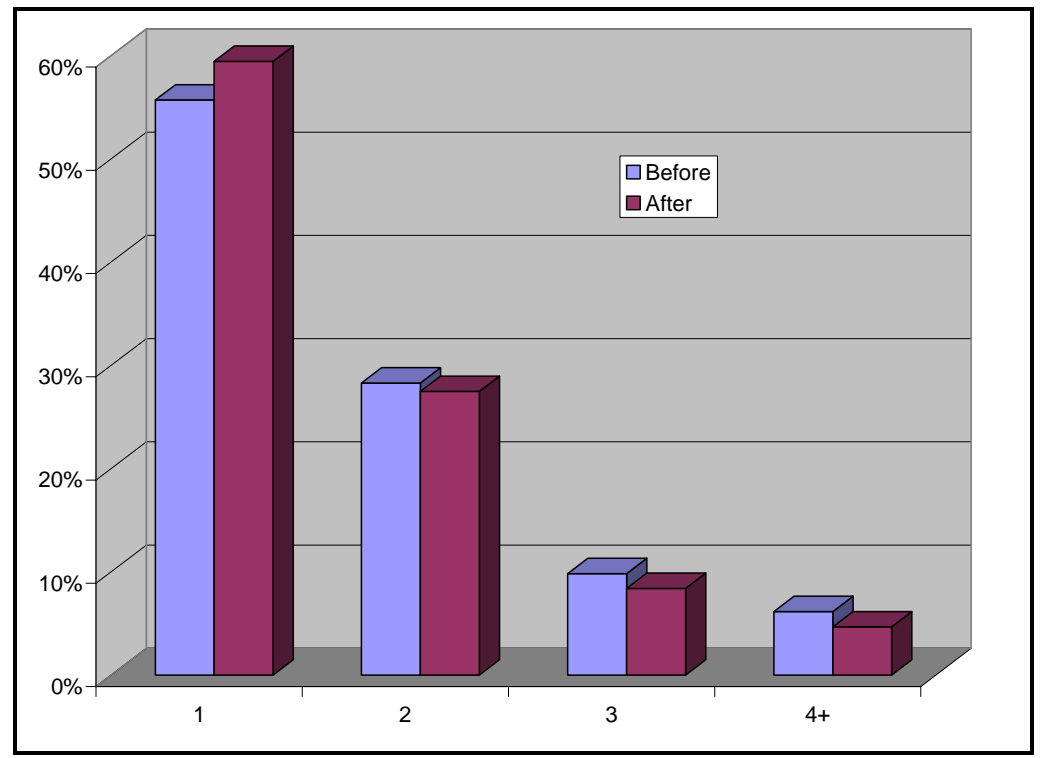

Figure 5.4. Number of occupants with 17-year-old drivers involved in crashes 
The induced exposure method was used to evaluate whether drivers were more likely to be responsible for a crash based on the number of occupants in the vehicle. The induced exposure for each age group by number of occupants before and after GDL is provided in Tables 5.1 to 5.5. As shown, all younger drivers were over-involved in crashes for all numbers of occupants both before and after GDL. Middle-aged drivers were under-represented for all numbers of occupants, as shown in Table 5.5.

As shown in Table 5.1, 14-year-old drivers were the most over-involved in crashes when they had four or more occupants, in the before period. Their involvement decreased in the after period for all categories, except for when they drove alone. Fourteen-year-olds were more likely to be responsible for the crash when they drove alone in the after period than for any other category. This suggests that additional benefits could be derived from restricting school licenses, which allow younger drivers to drive alone, and in enforcing the requirement for them to have a licensed adult in the vehicle.

Table 5.1. Induced exposure by number of occupants for 14-year-olds

\begin{tabular}{lcccc}
\hline & $\begin{array}{c}\text { 1 occupant } \\
\text { (driver only) }\end{array}$ & 2 occupants & 3 occupants & $\begin{array}{c}\text { 4 or more } \\
\text { occupants }\end{array}$ \\
\cline { 2 - 5 } Before & 2.23 & 2.65 & 2.53 & 3.39 \\
After & 2.63 & 2.61 & 2.06 & 2.16 \\
\hline
\end{tabular}

Results for 15-year-olds are provided in Table 5.2. In the before period, 15-year-olds; likelihood of being responsible for crashes increased as the number of occupants in the vehicle increased, with the highest exposure for 4 or more occupants. In the after period they were the least likely to be responsible for a crash when they had 4 or more occupants. Involvement was lower in the after period for all numbers of occupants for 15-year-olds. They were most likely to be responsible with one or two occupants in the vehicle in the after period. It should be noted that passenger age is unknown, so it is difficult to tell whether 14- and 15-year-olds are benefiting from having a supervising adult in the vehicle with them.

Table 5.2. Induced exposure by number of occupants for 15-year-olds

\begin{tabular}{lcccc}
\hline & $\begin{array}{c}\text { 1 occupant } \\
\text { (driver only) }\end{array}$ & 2 occupants & 3 occupants & $\begin{array}{c}\text { 4 or more } \\
\text { occupants }\end{array}$ \\
\cline { 2 - 5 } Before & 2.53 & 2.54 & 2.96 & 3.10 \\
After & 2.33 & 2.41 & 2.06 & 1.93 \\
\hline
\end{tabular}

Results for 16-year-old drivers are shown in Table 5.3. Involvement was lower for 16-year-olds in the after period for one or two occupants, but was slightly higher for three or four or more occupants. Seventeen-year-old drivers had lower involvement ratios overall than the younger teenage categories, as shown in Table 5.4. Involvement ratios were lower for all categories of occupants. 
Table 5.3. Induced exposure by number of occupants for 16-year-olds

\begin{tabular}{lcccc}
\hline & $\begin{array}{c}\text { 1 occupant } \\
\text { (driver only) }\end{array}$ & 2 occupants & 3 occupants & $\begin{array}{c}\text { 4 or more } \\
\text { occupants }\end{array}$ \\
\cline { 2 - 5 } Before & 2.02 & 2.21 & 2.26 & 2.41 \\
After & 1.94 & 2.16 & 2.29 & 2.97 \\
\hline
\end{tabular}

Table 5.4. Induced exposure by number of occupants for 17-year-olds

\begin{tabular}{lcccc}
\hline & $\begin{array}{c}\text { 1 occupant } \\
\text { (driver only) }\end{array}$ & 2 occupants & 3 occupants & $\begin{array}{c}\text { 4 or more } \\
\text { occupants }\end{array}$ \\
\cline { 2 - 5 } Before & 1.91 & 1.88 & 1.98 & 2.25 \\
After & 1.11 & 1.15 & 1.25 & 1.41 \\
\hline
\end{tabular}

As shown in Table 5.5, there was little change in crash involvement for the 35- to 44-year-old age group.

Table 5.5. Induced exposure by number of occupants for 35- to 44-year-olds

\begin{tabular}{lcccc}
\hline & $\begin{array}{c}\text { 1 occupant } \\
\text { (driver only) }\end{array}$ & 2 occupants & 3 occupants & $\begin{array}{c}\text { 4 or more } \\
\text { occupants }\end{array}$ \\
\cline { 2 - 5 } Before & 0.37 & 0.30 & 0.37 & 0.40 \\
After & 0.33 & 0.29 & 0.37 & 0.40 \\
\hline
\end{tabular}

\subsection{Time of Day}

Studies have also indicated that younger drivers are more likely to be involved in crashes during nighttime hours. The induced exposure method was used to evaluate the likelihood of younger drivers being responsible for crashes during certain times of the day. Not all hours of the day are shown.

Information by time of day for 14-year-olds is shown in Table 5.6. The relative nighttime involvement decreased sharply after implementation of GDL for the nighttime period from midnight to $6 \mathrm{AM}$, indicating that GDL restrictions may have been successful in reducing the nighttime accident risk for 14-year-old drivers. Relative involvement, however, increased for the $10 \mathrm{PM}$ to midnight time period, which is the time period with the highest accident risk. The involvement ratio remained high for the $8 \mathrm{PM}$ to $10 \mathrm{PM}$ and $7 \mathrm{AM}$ to $9 \mathrm{AM}$ time periods as well. 
Table 5.6. Induced exposure by time of day for 14-year-old drivers

\begin{tabular}{lcc}
\hline Time period & Before & After \\
\hline Midnight to 6 AM & 2.93 & 1.57 \\
7 AM to 9 AM & 3.53 & 3.37 \\
11 AM to 1 PM & 1.17 & 3.81 \\
3 PM to 5 PM & 2.30 & 2.51 \\
5 PM to 8 PM & 2.39 & 2.12 \\
8 PM to 10 PM & 3.19 & 3.09 \\
10 PM to midnight & 2.95 & 3.64 \\
\hline
\end{tabular}

The same information is provided for 15-year-old drivers in Table 5.7. The ratio of relative involvement for the midnight to 6 AM period remained unchanged for 15-year-old drivers after implementation of GDL. It also remained the period of highest accident involvement for 15year-olds. The accident risk did decrease for the 10 PM to midnight time period, which had the lowest risk for any time period after implementation of GDL.

Table 5.7. Induced exposure by time of day for 15-year-old drivers

\begin{tabular}{lcc}
\hline Time period & Before & After \\
\hline Midnight to 6 AM & 3.00 & 3.00 \\
7 AMto 9 AM & 2.20 & 2.49 \\
11 AM to 1 PM & 2.02 & 2.62 \\
3 PM to 5 PM & 2.60 & 2.48 \\
5 PM to 8 PM & 2.45 & 2.44 \\
8 PM to 10 PM & 2.63 & 2.32 \\
10 PM to midnight & 2.61 & 1.87 \\
\hline
\end{tabular}

Accident risk by time of day for 16-year-old drivers is shown in Table 5.8. The ratio of relative involvement did not decrease for any time period. The evening time periods (10 PM to midnight and midnight to $6 \mathrm{AM}$ ) were characterized by the lowest risk for the 16-year-old age group, however. The highest accident involvement risk occurs from 5 PM to 8 PM for 16-year-olds.

Table 5.8. Induced exposure by time of day for 16-year-old drivers

\begin{tabular}{lcc}
\hline Time period & Before & After \\
\hline Midnight to 6 AM & 1.63 & 2.12 \\
7 AMto 9 AM & 2.00 & 2.08 \\
11 AM to 1 PM & 2.14 & 2.25 \\
3 PM to 5 PM & 2.02 & 2.10 \\
5 PM to 8 PM & 2.26 & 2.68 \\
8 PM to 10 PM & 1.83 & 2.31 \\
10 PM to midnight & 1.50 & 1.85 \\
\hline
\end{tabular}

The same information is provided for 17-year-old drivers in Table 5.9. The ratio of relative involvement only decreased slightly for the 11 AM to 1 PM time period. The accident risk increased somewhat for the evening time periods (10 PM to midnight and midnight to $6 \mathrm{AM}$ ); the 
midnight to 6 AM time period had the highest accident involvement ratio for 17 -year-olds. The 8 to $10 \mathrm{pm}$ period had the lowest risk for 17 -year old drivers.

Table 5.9. Induced exposure by time of day for 17-year-old drivers

\begin{tabular}{lcc}
\hline Time period & Before & After \\
\hline Midnight to 6 AM & 1.18 & 2.13 \\
7 AMto 9 AM & 1.68 & 1.80 \\
11 AM to 1 PM & 1.73 & 1.66 \\
3 PM to 5 PM & 1.48 & 1.55 \\
5 PM to 8 PM & 1.64 & 1.71 \\
8 PM to 10 PM & 1.42 & 1.48 \\
10 PM to midnight & 1.14 & 1.51 \\
\hline
\end{tabular}




\section{SCHOOL LICENSING}

The GDL appears to have been successful for 14-, 16-, and 17-year-old drivers. Each of these age groups experienced a reduction in crash rate per licensed driver even after adjusting for the decrease in crash rate for middle-aged drivers, which was used to reflect an overall downward trend in crash rate.

The crash rate for 15-year-olds decreased at a much smaller rate than the decrease experienced by middle-aged drivers from the before to after period. If it is assumed that all drivers would have had a similar decrease in crashes from the before to the after period as experienced by the middle-aged drivers, then there is some evidence suggesting that the crash rate for 15-year-old drivers actually increased.

One factor that may have affected the effectiveness of GDL in reducing the crash rate for younger drivers is the influence of the school license. In Iowa, teenage drivers at all levels who hold instruction permits are allowed to hold school licenses, which allow them to drive unaccompanied to and from school, work, or school-related extracurricular activities. The number of drivers holding school license varies throughout the year. Numbers for December for each year in the before and after analysis periods were used to determine the number of school license holders compared to regular instruction permit holders. Data on school license holders were only available for 1997 and 1998 for the before period. Data from 2000, 2001, 2002, and 2003 were used for the after period.

The percentage of school license holders was relatively constant for 14-year-olds from the before to after period (5.9\% before versus $5.5 \%$ after) and 16 -year-olds ( $1.0 \%$ before versus $1.4 \%$ after). The percentage of school permit holders compared to the number of licensed drivers for 15-year-olds, however, was higher in the after period ( $23.0 \%$ before versus $26.7 \%$ after). Although it cannot be quantified, this may help explain why 15 -year-old drivers did not seem to benefit from implementation of the GDL program in Iowa.

The number of crashes by 14- and 15-year-old drivers was further analyzed for 2002 and 2003 by license type. Table 6.1 indicates number of crashes by type of license for both age groups. Fourteen-year-old drivers were involved in a total of 356 crashes in 2002 and 2003. In 97 cases, the reporting officer did not indicate license status. In most cases, it is assumed that the reporting officer did not fill in the information; however, in some cases, it may indicate that the driver was not licensed at the time of the crash or was licensed in another state.

The average number of 14-year-old drivers holding each type of license was determined using an average value from December for both years. Only $6.0 \%$ of 14 -year-old drivers held a school permit but they were involved in almost $31 \%$ of the crashes for that age group where license status was known. Thus, 14-year-olds with a school license were more than seven times more likely to be involved in a crash than 14-year-olds who were operating under a regular instruction permit. 
Since teenage drivers who hold school permits may be more likely to make trips than regular instruction permit holders, their exposure was determined using the induced exposure method. All two-vehicle crashes involving a 14-year-old driver for 2002 and 2003 were extracted, and the person most likely to responsible for the crash was determined. If it is assumed that nonresponsible drivers represent the on-road driver population, 14-year-olds who held school licenses made up $23.5 \%$ of the 14 -year-old drivers on the road, even though they only represent $6 \%$ of 14-year-old drivers. This indicates that 14 -year-old drivers with school permits are doing significantly more driving than their peers with regular instruction permits.

The same information is provided for 15-year-old drivers in Table 6.1. As shown, 15-year-olds were involved in a total of 1,423 crashes in 2002 and 2003. Of those, the license type was not indicated by the officer for 222 crashes; this may have been due to non-reporting by the officer, a driver without a license, or a driver from another state. The average number of 15-year-old drivers holding each type of license was determined using an average value from December for both years. Only $28.4 \%$ of 15 -year-old drivers held a school license, but they were involved in almost $71.1 \%$ of the crashes for that age group where license type was known. Thus, 15-year-old drivers with a school license were than 6.2 times more likely to be involved in a crash than 15year-olds who were operating under a regular instruction permit.

Exposure for 15-year-old drivers was also determined using the induced exposure method. All two-vehicle crashes involving a 15-year-old driver for 2002 and 2003 were extracted and the person most likely to responsible for the crash was determined. If it is assumed that nonresponsible drivers represent the on-road driver population, 15-year-olds who held school permits made up $67.4 \%$ of the 15 -year-old drivers on the road, even though they only make up $28.4 \%$ of 15 -year-old driver population. This indicates that 15 -year-old drivers with school license are doing significantly more driving than their peers with regular instruction permits.

Table 6.1. Crashes for 2002 and 2003 by type of license holder for 14- and 15-year-olds

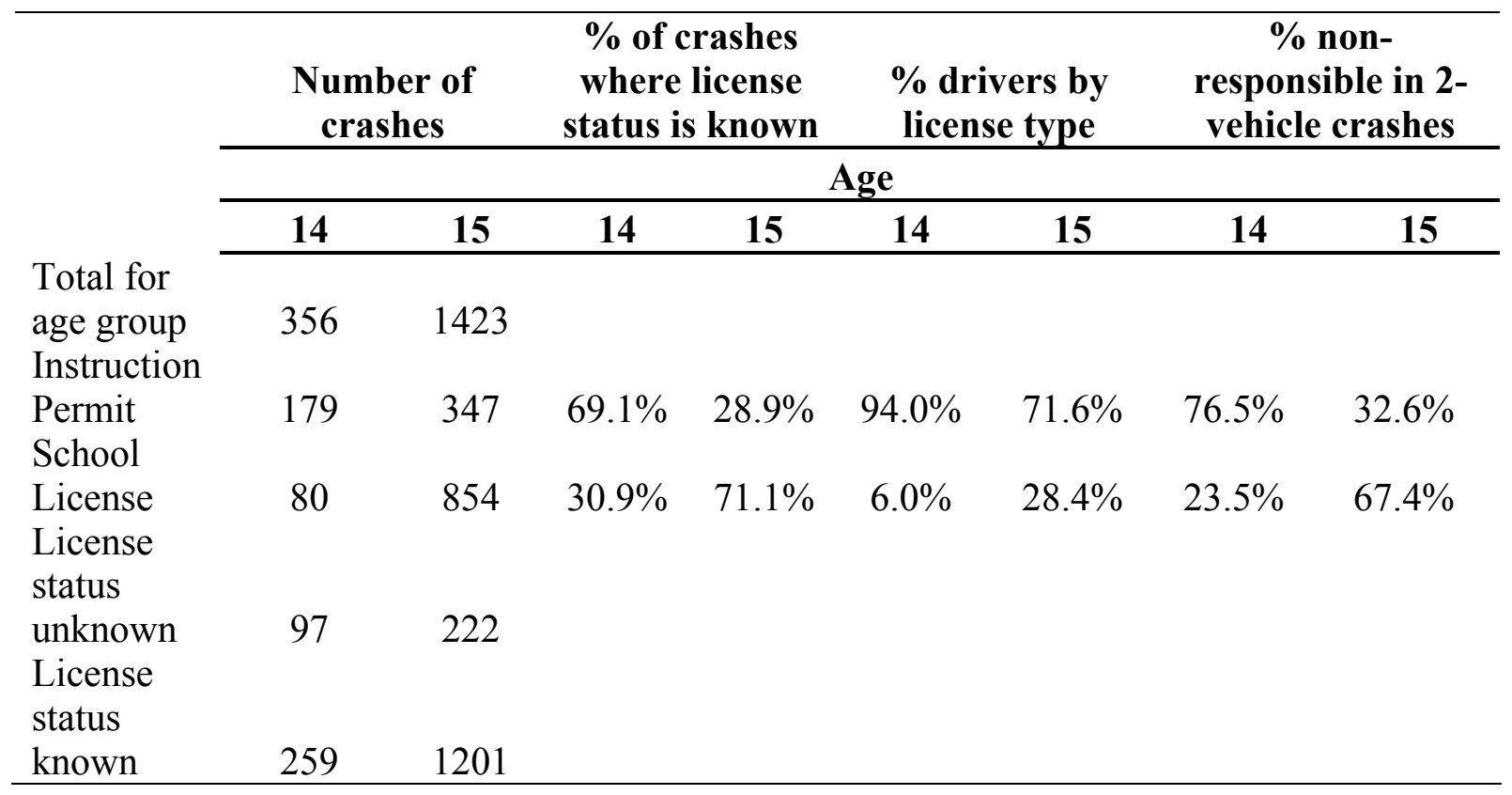


Information about sanctions and moving violation convictions was also obtained for 14- and 15year-old drivers. This information was only available from the Iowa Department of Motor Vehicles for the most recent 6 month period (September 2004 to April 2005); it is presented in Table 6.2. Information was only available for 14- and 15-year-olds together. As shown, 14- and 15-year-old school license holders are 7.7 times more likely to have one or more sanctions than their peers with a regular instruction permit. They are also 4.8 times more likely to receive one or more moving convictions.

Table 6.2. Sanctions and moving violations for 14- and 15-year-old drivers by license type for September 2004 to April 2005

\begin{tabular}{|c|c|c|c|c|c|}
\hline \multicolumn{6}{|c|}{ Drivers with sanctions by the number of sanctions } \\
\hline & None & 1 & 2 & $3+$ & Total \\
\hline Instruction permit & 48,799 & 341 & 65 & 53 & 49,258 \\
\hline School license & 8,068 & 541 & 59 & 25 & 8,693 \\
\hline \multicolumn{6}{|c|}{ Drivers With Moving Violation Convictions by the Number of Convictions } \\
\hline & None & 1 & 2 & $3+$ & Total \\
\hline Instruction Permit & 48,453 & 524 & 189 & 92 & 49,258 \\
\hline School License & 8,009 & 545 & 121 & 18 & 8,693 \\
\hline
\end{tabular}




\section{SUMMARY AND CONCLUSIONS}

The effectiveness of the graduated drivers licensing program was evaluated for Iowa. A GDL was implemented in 1999. Crashes were evaluated for a four-year period before GDL was instituted and for a four-year period after. The Iowa GDL took effect in 1999; thus, the before period was made up of crash data for 1995, 1996, 1997, and 1998. Crash data for 1999 were excluded, since some young drivers that year were a product of the GDL and others were not. The after period included crash data for 2000, 2002, 2003, and 2004. The Iowa DOT crash reporting form changed in 2001 and, due to problems during the transition, data quality was uncertain. Consequently, crash data for 2001 were not used in the analysis.

The crash form used to report crashes for Iowa changed in 2001. Certain fields were changed, others were deleted, and some new fields were added. As a result, some discrepancies existed between the way in which crashes were reported before and after implementation of GDL. Reporting requirements for crashes also changed from the before to after period as well. As a result, the number of yearly crashes reported for the entire state decreased after 2000. In order to account for factors other than GDL that may have influenced crashes from the before to after period, reductions in younger driver crash rates were compared to the reduction in crash rate for 35- to 44-year-old drivers. It is assumed that the middle-aged driver group represents a stable group. They were used as a comparison group to reflect what happened in crashes overall independent of implementation of GDL. If the younger driver crash rate was not influenced by GDL, they would be expected to have a decrease in crashes that was similar to the middle-aged driver group. The decrease in crashes for each younger driver age group was compared to the middle-aged driver group.

Before implementation of GDL, the crash rates per licensed driver for 14- and 15 -year-old drivers were somewhat lower than the crash rate for the middle-aged group. The 16- and 17year-old drivers had crash rates that were significantly higher than the middle-aged age group before implementation of GDL. After implementation of GDL, the crash rate for all age groups was lower than in the before period. The 35- to 44-year-old age group experienced a $21.6 \%$ reduction in crashes from the before to after period. All teenage groups experienced a greater decrease in crash rate than the 35- to 44-year-old age group, except for the 15-year-olds who experienced a smaller decrease. The reduction in crash rate was the greatest for 14-year-olds. The crash rate was almost $43 \%$ lower for this age group in the after period than in the before period. The smallest reduction in crash rates from the before to after period was for 15-year-old drivers with a reduction around $15 \%$, which was lower than reduction for middle-aged drivers. If it is assumed that 15-year-old drivers should have had at least the same reduction in crashes as the middle-aged group, whose decrease was attributed to the change in the way and types of crashes are reported, then there is some evidence that the crash rate for 15-year-old drivers actually increased. The crash rate for 16-year-olds was reduced by $30 \%$. The 17 -year-old age group experienced a slightly higher reduction in crashes $(25 \%)$ than 35 - to 44 -year-olds.

The results for the 15-year-old age group were unexpected. The rate of compliance to GDL restrictions for any age group is unknown, so the effect of compliance could not be evaluated. Section 5.4 discussed the change in the number of teenagers who drove alone before and after implementation of GDL. Both 14- and 16-year-old drivers had a decrease in the number of 
drivers involved in accidents who were driving alone. Although this only represents occupancy for those involved in accidents - whether a second occupant is an adult is unknown - this tends to suggest that 14-year-old and 16-year-olds are more likely to be driving with someone else in the car after implementation of GDL. It should also be noted that a large number of teenagers in all age groups were still driving alone after GDL. For the 15-year-old age group, the number of drivers who drove alone increased slightly ( $45 \%$ to $50 \%$ ) after implementation of GDL, even though 15-year-olds are under the instruction permit and are required to have a licensed adult in the car.

The impact of the school license on crashes was also explored and presented. In general, school license holders make up only a small proportion of 14- and 15-year-old drivers but are disproportionately more likely to be involved in a crash or be convicted of a moving violation than regular instruction permit holders.

Foss and Goodwin (2003) indicate that many GDL programs in the U.S. are not structured to achieve maximum benefits and, therefore, may not be as effective as possible. For instance, nighttime driving restrictions begin too late, many programs have no limits on passengers, and allow supervising drivers who are too young. Other programs are not structured to make sure that the learning process is useful and do not address amount and type of driving that new drivers should obtain (for example, the permit period may be too short or may not specify desired amount of practice). As an example, Foss and Goodwin state that only 3\% of 16- and 17-yearold trips occurred from midnight to $6 \mathrm{AM}$, but many states choose this time period to put nighttime driving restrictions in place. The researchers cite a statistic from another source indicating that the fatal crash risk for 16- and 17-year-olds is three times higher between 10 PM and midnight than during the daytime, but as the majority $(2 / 3)$ of states have nighttime driving restrictions that begin at midnight or later, the most critical nighttime hours are not restricted. 


\subsection{RECOMMENDATIONS}

Iowa's GDL appears to have been effective for 14-, 16-, and 17-year old drivers. As indicated, 15- year-old drivers did not experience a reduction in crash rate that was greater than the reduction for 35- to 44-year-olds. This may be due to several factors, including use of the school license, which allows drivers with instruction permits who would otherwise only be allowed to drive supervised by a parent or other adult to regularly drive alone. This provision seems counter-effective to the purpose of the GDL program, which requires supervised driving so teenagers can practice before they are allowed to face the driving situation on their own.

Although a teenage driver with a school permit is only allowed to drive alone to and from work, school, and school events (and should be using the most direct route), an officer who stops a solo teenage driver with a school license has no way of verifying whether the teenager is actually going to and from a school event or work or is taking the most direct route. This may encourage both teenage drivers and parents to misuse the school license.

The use of the school license should be reconsidered in light of the evidence presented and the goals of the GDL. Enforcing the restrictions of the school license could also be considered. Having teenage drivers with school permits obtain an official record of the most direct path from their school or work to home or vise versa, and school or work times, and requiring that this information be presented when an officer stops a teenage driver may encourage appropriate use of the school license. Schools may be encouraged to restrict issuing school licenses, except in the case of demonstrated need.

Other recommendations for improvements to the GDL program in Iowa include restricting the number of teenage passengers in the vehicle and expanding nighttime driving restrictions. This is based on results of the research, which indicate that these are problematic situations for young drivers. 


\section{REFERENCES}

Begg, D and Stephenson, S. "Graduated Driver Licensing: the New Zealand Experience. Journal of Safety Research.” Vol. 34, No. 1. 2002. pp. 99-105.

Davis, Gary A. and Shimin Yang. 2001. "Bayesian Identification of High-Risk Intersections for Older Drivers via Gibbs Sampling." Journal of the Transportation Research Record 1746. pp. 8489.

Falb, S. Five-Year Study of Iowa's Driver Improvement Program: A Study of Participant Demographics and Participants' Performance Following Driver Improvement Program Attendance. Iowa Department of Transportation. 2002.

Ferguson, S. "Other High-risk Factors for Young Drivers-How Graduated Licensing Does, Doesn't, or Could Address them.” Journal of Safety Research, Vol. 34, No. 1, pp. 71-77.

Foss, at el, R and Goodwin, A. "Enhancing the Effectiveness of Graduated Driver Licensing Legislation." Journal of Safety Research, Vol. 34, No. 1, 2003, pp. 79-84.

Golias, John, and George Yannis. (2001). Dealing with Lack of Exposure Data in Road Accident Analysis. Traffic Safety on Three Continents Conference, Moscow, Russia.

Hauer, Ezra. Observational Before—After Studies in Road Safety. Pergamon, New York. 1997.

IIHS, 2001. A Blueprint for Graduated Licensing, April 2001. Insurance Institute for Highway Safety. http://www.hwysafety.org/safety_facts/teens/blueprint.pdf, accessed September 19, 2001.

Iowa DOT. Iowa Driver's Manual. 1999-2000, pp. 7-8.

Iowa DOT, 2001. Graduated Driver Licensing System.

http://www.dot.state.ia.us/mvd/ods/gdl.htm, accessed September 19, 2001.

Lam, Lawrence T. "Factors associated with young drivers' car crash injury: comparisons among learner, provisional, and full licensees." Accident Analysis \& Prevention. Volume 35, Issue 6. November 2003. pp. 913-920.

Lin, M. and K. Fearn. "The Provisional License: Nighttime and Passenger Restrictions: a Literature Review.” Journal of Safety Research. Vol. 34, No. 1. 2003. pp. 51-61.

Mayhew, Daniel R., Herbert M. Simpson, and Anita Pak. 2003. "Changes Is Collision Rates Among Novice Drivers During The First Months Of Driving." Accident Analysis and Prevention. Vol 5. pp. 683-691.

McCartt, Anne T., William A. Leaf, Charles M. Farmer, Susan A. Ferguson, Allan F. Williams. "Effects of Florida's graduated licensing program on the behaviors and attitudes of teenagers." Journal of Safety Research 32. 2001. pp. 119- 131. 
McCartt, Anne T. and Veronika Shabanova Northrup. "Factors related to seat belt use among fatally injured teenage drivers." Journal of Safety Research 35 (2004) 29-38.

Memmer, S. AAA-OK: Driver-ZED Training Program for Youth. Edmunds, December 27, 2000, pp. 1-3.

Ott, R. Lyman and Michael Longnecker. An Introduction to Statistical Methods and Data Analysis. Duxbury, Thomson Learning. Pacific Grove, CA. 2001.

National Highway Traffic Safety Association. Saving Teenage Lives. http://www.nhtsa.dot.gov/people/injury/newdriver/SaveTeens/html, accessed December 30, 2003.

National Highway Traffic Safety Association. Graduated Driver Licensing System. http://www.nhtsa.dot.gov/people/outreach/safesobr/19qp/factsheets/graduated.html, accessed January 7, 2004.

Preusser, David F., Susan A. Ferguson, Allan F. Williams. "Source Effect of teenage passengers on the fatal crash risk of teenage drivers." Accident Analysis and Prevention. Vol 30, n 2. Mar 1998. pp. 217-222.

Rice, Thomas M., Corinne Peek-Asa, and Jess F. Kraus. Effects of the California Graduated Driver Licensing Program. Journal of Safety Research. Volume 35. No. 4. 2004. pp. 375-381.

Simons-Morton, Bruce G. and Jessica L. Hartos. "How well do parents manage young driver crash risks?” Journal of Safety Research 34 (2003) 91-97

Srinivasan, R. Evaluation of Graduated Driver Licensing in New Jersey: Phase 1. New Jersey DOT. July 2002, pp. 22-25.

Stamatiadis, Nikiforos and John A. Deacon. Trends in Highway Safety: Effects of an Aging Population on Accident Propensity. Accident Analysis and Prevention. Vol. 27, No. 4. pp. 443459. 1995.

Stamatiadis, Nikiforos and John A. Deacon. (1997). Quasi-Induced Exposure: Methodology and Insight. Accident Analysis and Prevention, Vol. 29, No. 1, pp. 37-52.

Ulmer, R. G., A.F. Williams, and D.F. Preusser. "Crash involvements of 16-year-old drivers." Journal of Safety Research. 28(2). 1997. pp. 97- 103.

Ulmer, R. G., D.F. Preusser, A.F. Williams, S.A. Ferguson, and C.M. Farmer. "Effect of Florida's graduated licensing program on the crash rate of teenage drivers." Accident Analysis and Prevention. 2000. 32(4). pp. 527-532.

Ulmer, Robert G., Susan A. Ferguson, Allan F. Williams, and David F. Preusser. "Teenage Crash Reduction Associated with Delayed Licensure in Connecticut." Journal of Safety Research. Vol. 32. 2001. pp. 31-41. 
University of North Carolina, Highway Safety Research Center. Preliminary Evaluation of the North Carolina Graduated Driver Licensing System: Effects on Young Driver Crashes. July 2000. http://www.hsrc.unc.edu/pdf/2000/gdlpdf.pdf, Accessed December 30, 2003.

University of North Carolina, Highway Safety Research Center. The North Carolina Graduated Driver Licensing System: Urban-Rural Differences. February 2001.

http://www.hsrc.unc.edu/pdf/gdl/Gdl_02_25.PDF, Accessed December 30, 2003.

U.S. Department of Transportation and Federal Highway Administration. Driving is More

Dangerous for New Drivers. http://safety.fhwa.dot.gov/roaduser/new.htm, accessed July 2004.

Williams, Allan F., David F. Preusser, Susan A. Ferguson, and Robert G. Ulmer. Analysis of the Fatal Crash Involvements of 15-year-old drivers. Journal of Safety Research. Volu 28, No. 1. 1997. pp. 49-54.

Williams, A.F., S.A. Ferguson, W.A. Leaf and D.F. Preusser. "Views of Parents of Teenagers about Graduated Licensing Systems." Journal of Safety Research. Vol. 29, No. 1. 1998. pp. 1-7.

Williams, A. Teenage Passengers in Motor Vehicle crashes: A Summary of Current Research. Insurance Institute of Highway Safety. December 2001.

Williams, A. "Graduated Licensing in the United States." Institute of Transportation Engineers (ITE) Journal. September 2003. pp. 28-30. 